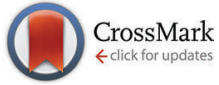

Cite this: Phys. Chem. Chem. Phys., $2015,17,16525$

Received 6th April 2015, Accepted 22nd May 2015

DOI: $10.1039 / c 5 c p 01993 a$

www.rsc.org/pccp

\title{
Interplay of donor-acceptor interactions in stabilizing boron nitride compounds: insights from theory $\dagger$
}

\author{
Mohammad R. Momeni, Lisa Shulman, Eric Rivard* and Alex Brown*
}

\begin{abstract}
The stability of a variety of linear and cyclic $(B N)_{n}(n=1-3)$ adducts with $\mathrm{N}$-heterocyclic carbene $\left(I m \mathrm{Me}_{2} ; \mathrm{ImMe} \mathrm{I}_{2}=\left[(\mathrm{HCNMe})_{2} \mathrm{C}:\right]\right)$, N-heterocyclic olefin $\left(\operatorname{ImMe} \mathrm{CH}_{2}\right)$ and Wittig $\left(\mathrm{Me}_{3} \mathrm{PCH}_{2}\right)$ donors has been examined using M05-2X/cc-pVTZ computations. The strength and nature of the bonds have been investigated using natural bond orbital (NBO) and atoms-in-molecules (AIM) analyses. Complementary energy decomposition analysis (EDA-NOCV) has been carried out based on BP86/TZ2P computations. In agreement with NBO and AIM analyses, the orbital interaction energy obtained from EDA contributes at least $50 \%$ to the total attractive interactions for the carbon-boron bonds indicating their largely covalent nature. The feasibility of isolating monomeric $(B N)_{n}$ units using a donor/acceptor protocol was also investigated in a series of adducts of the general form: LB. $(B N)_{n} \cdot B H_{3}$ and LB. $(B N)_{n} \cdot W(C O)_{5}(n=1-3$; $\mathrm{LB}=$ Lewis bases). Moreover, EDA-NOCV analysis of $I m \mathrm{me}_{2} \cdot \mathrm{BN} \cdot \mathrm{W}(\mathrm{CO})_{5}$ and $I \mathrm{mMe}_{2} \cdot \mathrm{B}_{3} \mathrm{~N}_{3} \cdot \mathrm{W}(\mathrm{CO})_{5}$ shows that the carbene-boron bonds are stronger in the presence of $W(C O)_{5}$ as a Lewis acid mainly because of a dramatic decrease in the amount of Pauli repulsion rather than an increase in the electrostatic/orbital attraction terms.
\end{abstract}

\section{Introduction}

Boron nitride materials $(\mathrm{BN})_{n}$ are isoelectronic with various carbon allotropes (e.g., diamond, graphene, nanotubes) ${ }^{1-3}$ however, they possess vastly different properties due to the presence of polarized B-N linkages. Two specific properties, wide electronic band gaps (5.9 eV in hexagonal $\mathrm{BN}$ ) and chemical inertness, ${ }^{4}$ make boron nitride of significant interest for the electronics industry, with the construction of devices based on BN/graphene heterostructures being a promising recent development. ${ }^{5,6}$ One hindrance to the widespread examination and application of BN materials is the harsh conditions required for their syntheses, i.e., heating above $900{ }^{\circ} \mathrm{C}$ and/or the use of plasma conditions. ${ }^{1-3}$ With these challenges in mind, we have embarked on a program wherein complexes of the

Department of Chemistry, University of Alberta, Edmonton, Alberta, T6G $2 G 2$ Canada.E-mail: erivard@ualberta.ca, alex.brown@ualberta.ca;

Fax: +1-780-492-8231; Tel: +1-780-492-4255, +1-780-492-1854

$\dagger$ Electronic supplementary information (ESI) available: NICS values for all the $\mathrm{B}_{2} \mathrm{~N}_{2}$ and $\mathrm{B}_{3} \mathrm{~N}_{3}$ species (Table S1), NBO results for all the species (Tables S2-S9), M05-2X/cc-pVTZ computed gas phase $X Y Z$ coordinates for all the structures (Table S10), BP86/TZ2P computed gas phase $X Y Z$ coordinates for all the monosubstituted adducts (Table S11), M05-2X/cc-pVTZ computed gas phase complexation energies for the Lewis acid bound adducts (Table S12), M05-2X/cc-pVTZ optimized structures of the isolated species in the gas phase (Fig. S1), AIM results for all the species (Fig. S2), and frontier molecular orbitals of all the studied systems (Fig. S3). See DOI: 10.1039/c5cp01993a general form $[\mathrm{LB} \cdot \mathrm{BN}]_{n}$ ( $n \geq 1$; LB = Lewis base) might be formed with suitable carbon-based donors. Upon heating in solution, the target $[\mathrm{LB} \cdot \mathrm{BN}]_{n}$ complexes could afford bulk boron nitride and free Lewis base. To provide a solid fundamental basis for future experimental explorations, we present quantum mechanical computations on the Lewis base-stabilized linear and cyclic boron nitride species $(\mathrm{BN})_{n}(n=1-3)$ including the donor-acceptor adducts LB·(BN $)_{n} \cdot$ LA $(n=1-3$, LA $=$ Lewis acid). Recent examples of stabilizing main group element units (e.g., $\mathrm{Si}_{2}$ ) with the aid of strong carbon-based donors are numerous in the literature. ${ }^{7-15}$ Moreover, donor-acceptor stabilization has been used to great success to isolate heavier group 13-15 element species, ${ }^{16-21}$ while related computational studies have been reported. ${ }^{22,23}$ More specifically, DFT predicted a significant thermodynamical stabilization of group 13-15 cubane systems (e.g., $\mathrm{B}_{4} \mathrm{~N}_{4}$ ) upon addition of $\mathrm{NH}_{3}$ and $\mathrm{BH}_{3}$ as donor and acceptor molecules, respectively. ${ }^{22}$

In this work we present our analyses of the bonding within Lewis base-substituted boron nitride compounds in the presence and/or absence of Lewis acid. Specifically we examined the binding of the carbon-based donors, $\operatorname{ImMe}_{2}\left(\operatorname{ImMe}_{2}=\left[(\mathrm{HCNMe})_{2} \mathrm{C}:\right]\right)$, ImMe ${ }_{2} \mathrm{CH}_{2}$ and $\mathrm{Me}_{3} \mathrm{PCH}_{2}$ to $(\mathrm{BN})_{n}$ units, given our use of their sterically hindered analogues to bind/stabilize inorganic methylene and ethylene units $\left(\mathrm{EH}_{2}\right.$ and $\mathrm{H}_{2} \mathrm{EE}^{\prime} \mathrm{H}_{2} ; \mathrm{E}$ and $\mathrm{E}^{\prime}=\mathrm{Si}$, Ge and/or $\mathrm{Sn}) \cdot{ }^{14,24-31}$ We also provide computations on $\mathrm{LB} \cdot(\mathrm{BN})_{n} \cdot \mathrm{BH}_{3}$ and LB. $(\mathrm{BN})_{n} \cdot \mathrm{W}(\mathrm{CO})_{5}$ adducts $(n=1-3)$ featuring coordinated $(\mathrm{BN})_{n}$ units 
and show that this overall donor-acceptor approach is a viable means of intercepting a complex of molecular boron nitride. Finally, based on detailed EDA-NOCV computations, we will comment on the strength and nature of both the carbene-boron and nitrogen-tungsten donor acceptor bonds in the $\mathrm{ImMe}_{2}$ substituted $\mathrm{BN} \cdot \mathrm{W}(\mathrm{CO})_{5}$ and $\mathrm{B}_{3} \mathrm{~N}_{3} \cdot \mathrm{W}(\mathrm{CO})_{5}$ adducts.

\section{Computational methods}

Geometry optimizations were performed using density functional theory (DFT) with the M05-2X ${ }^{32}$ functional. The computations employed the following basis sets: cc-pVTZ ${ }^{33,34}$ for all period 1, 2 and 3 atoms and cc-pVTZ-PP, ${ }^{35,36}$ combined with the corresponding small core (60 electrons) effective core potential (ECP) for tungsten (W). The basis set and ECP for tungsten were obtained from the basis set exchange. ${ }^{37,38}$ For convenience, these computations are simply labeled as M05-2X/cc-pVTZ throughout the text. Triplet states for $\mathrm{BN}$, linear $\mathrm{BNBN}$, and cyclic $\mathrm{B}_{2} \mathrm{~N}_{2}$ were computed using an UHF reference. For geometry optimizations, "Tight" convergence criteria were applied: maximum force = $1.5 \times 10^{-5}$ a.u., RMS force $=1.0 \times 10^{-5}$ a.u., maximum displacement $=6.0 \times 10^{-5}$, and RMS displacement $=4.0 \times$ $10^{-5}$. The grid used for numerical integration in DFT was set to "Ultrafine" with a pruned grid of 99 radial shells and 590 angular points per shell. Harmonic vibrational frequencies were computed analytically at the same level of theory in order to characterize the stationary points as minima, representing equilibrium structures on the potential energy surfaces.

Energy decomposition analyses (EDA) were performed for all the mono-substituted complexes using the GGA BP86 density functional $^{39,40}$ and the TZ2P basis set; ${ }^{41}$ relativistic effects were considered for the tungsten atom using the ZORA approximation. As originally developed by Morokuma, ${ }^{42}$ Ziegler and Rauk, ${ }^{43}$ EDA analysis can provide valuable insight into the nature and strength of a bond. It decomposes the bond dissociation energy $\left(D_{\mathrm{e}}\right)$ between two fragments (A and B) into the interaction energy $\left(\Delta E_{\text {int }}\right)$ and the preparation energy $\left(\Delta E_{\text {prep }}\right)$ :

$$
-D_{\mathrm{e}}=\Delta E_{\mathrm{int}}+\Delta E_{\mathrm{prep}}
$$

The preparation energy, which pertains to the amount of energy required to distort and/or electronically excite the two fragments to their states in the complex, is defined as:

$$
\Delta E_{\text {prep }}=E_{\mathrm{A}}-E_{\mathrm{A}}^{0}+E_{\mathrm{B}}-E_{\mathrm{B}}^{0} .
$$

$E_{\mathrm{A} / \mathrm{B}}$ and $E_{\mathrm{A} / \mathrm{B}}^{0}$ are the energies of the fragments for their geometries in the complex and as free ligands, respectively. To obtain these energies, all of the boron nitride, Lewis basic (LB) and Lewis acidic (LA) molecules as well as their complexes were re-optimized at the BP86/TZ2P level of theory. When the optimized geometries for the M05-2X/cc-pVTZ and BP86/TZ2P methods were compared, no significant differences were observed, see discussion in (ESI $\dagger)$.

The interaction energy $\left(\Delta E_{\text {int }}\right)$ can be decomposed into three terms: (1) the Pauli exchange repulsion term $\left(\Delta E_{\text {Pauli }}\right)$, (2) the electrostatic interaction energy $\left(\Delta E_{\text {elstat }}\right)$ between charge densities of the fragments, and (3) the orbital interaction energy $\left(\Delta E_{\text {orb }}\right)$ which results from orbital mixing of the A and B fragments:

$$
\Delta E_{\text {int }}=\Delta E_{\text {Pauli }}+\Delta E_{\text {elstat }}+\Delta E_{\text {orb }}
$$

The first term $\left(\Delta E_{\text {Pauli }}\right)$ is always positive while in most cases $\Delta E_{\text {elstat }}$ and $\Delta E_{\text {orb }}$ are negative. For more information regarding this method and its application in studying chemical bonds including donor-acceptor complexes the reader is referred to the literature. ${ }^{44-48}$

The natural orbitals for chemical valence (NOCV) approach can be utilized to obtain both a qualitative and quantitative picture of the chemical bond (eqn (4)). ${ }^{49}$ In this approach, the deformation density $\Delta \rho(r)$ is decomposed into pairwise $\psi_{k}$ and $\psi_{-k}$ complementary eigenfunctions (NOCVs) with eigenvalues of $\nu_{k}$ and $\nu_{-k}$ that have the same magnitude but opposite sign:

$$
\Delta \rho(r)=\sum_{k=1}^{N / 2} v_{k}\left[-\psi_{-k}^{2}(r)+\psi_{k}^{2}(r)\right] .
$$

Positive and negative values describe, respectively, density accumulation and density depletion; the bond forms through flowing electron density from the negative part of the molecule (shown later in red color) to the positive part (shown in blue). For quantitative results, one can represent the orbital interaction energy in terms of the NOCV eigenvectors:

$$
\Delta E_{\mathrm{orb}}=\sum_{k=1}^{N / 2} v_{k}\left[-F_{-k,-k}^{\mathrm{TS}}+F_{k, k}^{\mathrm{TS}}\right] .
$$

where $F_{-k,-k}^{\mathrm{TS}}$ and $F_{k, k}^{\mathrm{TS}}$ are diagonal transition state Kohn-Sham matrix elements over the corresponding NOCVs. Therefore, eqn (4) and (5) provide the qualitative and quantitative pictures of a chemical bond even for asymmetric complexes. For further details on this approach please see the original paper. ${ }^{49}$

The nature of the bonding in the Lewis base (LB) substituted adducts was also assessed using both natural bonding orbital $(\mathrm{NBO})^{50}$ and atoms-in-molecules (AIM) ${ }^{51}$ analyses. NBO population analyses were done at the M05-2X/cc-pVTZ level of theory by using the NBO suite available in Gaussian 09. ${ }^{52}$ AIM analyses were carried out at the same level of theory using the AIMALL software package. ${ }^{53}$ Nucleus independent chemical shift (NICS) ${ }^{54}$ computations were also performed using the gauge-independent atomic orbital (GIAO) method at the center of and $1 \AA$ above the ring at the M05-2X/cc-pVTZ level of theory. All the electronic structure calculations were performed using Gaussian $09^{52}$ and ADF $2013^{55}$ packages.

\section{Results and discussion}

As mentioned in the Introduction, the use of N-heterocyclic carbene (NHC), ${ }^{56-58} \mathrm{~N}$-heterocyclic olefin (NHO) $)^{59-66}$ and Wittig $\left(\mathrm{R}_{3} \mathrm{PCR}_{2}^{\prime}\right)^{31,67,68}$ donors is becoming prevalent in main group element chemistry. Accordingly $\mathrm{ImMe}_{2}, \mathrm{ImMe}_{2} \mathrm{CH}_{2}$ and $\mathrm{Me}_{3} \mathrm{PCH}_{2}$ were chosen as donors within the boron nitride adduct series shown in Fig. 1.

The isolated $(\mathrm{BN})_{2}$ and $(\mathrm{BN})_{3}$ species, as well as higher oligomers, have been the subjects of numerous computational 


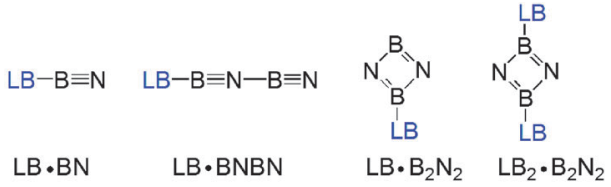

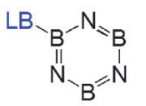

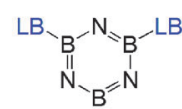

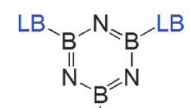$$
\text { LB }
$$$$
\mathrm{LB} \cdot \mathrm{B}_{3} \mathrm{~N}_{3}
$$

$\mathrm{LB}_{2} \cdot \mathrm{B}_{3} \mathrm{~N}_{3}$

$\mathrm{LB}_{3} \cdot \mathrm{B}_{3} \mathrm{~N}_{3}$

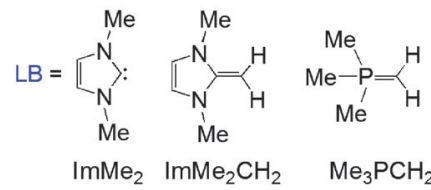

Fig. 1 Lewis base $(\mathrm{LB})$ bound $(\mathrm{BN})_{n}(n=1-3)$ complexes considered in this study.

investigations; ${ }^{69-74}$ monomeric BN has also been studied extensively ${ }^{75-77}$ The isolated systems are not the focus of the present study, however, results for the isolated species are reported for the corresponding isomers considered in the complexes for completeness. The isolated $(\mathrm{BN})_{n}(n=1-3)$ molecules are discussed in the ESI. $\dagger$

\subsection{Geometries of the Lewis base (LB) adducts LB. $(\mathrm{BN})_{n}(n=1-3)$}

The M05-2X/cc-pVTZ optimized geometries of the mono-ligated boron nitride oligomers, LB.(BN $)_{n}(n=1-3)$, are depicted in Fig. $2\left(\mathrm{LB}=\mathrm{ImMe}_{2}, \mathrm{ImMe}_{2} \mathrm{CH}_{2}\right.$, and $\left.\mathrm{Me}_{3} \mathrm{PCH}_{2}\right)$; see Fig. S1, ESI $\dagger$ for the optimized structures of the isolated species.

In each case, the carbon-based donors were bound to electron deficient boron sites, in line with prior adduct formation with amino-boranes $\left(\mathrm{R}_{2} \mathrm{~N}-\mathrm{BH}_{2}\right) \cdot{ }^{78-81}$ The NHC-bound adducts of the $\mathrm{BN}$ chains, $\mathrm{ImMe}_{2} \cdot \mathrm{BN}$ and $\mathrm{ImMe}_{2} \cdot \mathrm{BNBN}$, each adopt linear $\mathrm{C}_{\text {ImMe2 }}-(\mathrm{BN})_{n}$ configurations; geometry optimizations initiated with non-linear configurations return to linearity. On the other hand, appreciably bent $\mathrm{C}-\mathrm{B}-\mathrm{N}$ and intrachain $\mathrm{N}-\mathrm{B}-\mathrm{N}$ angles are found within the related $\mathrm{ImMe}_{2} \mathrm{CH}_{2}$ and $\mathrm{Me}_{3} \mathrm{PCH}_{2}$-capped boron nitride adducts. For example, the $\mathrm{C}-\mathrm{B}-\mathrm{N}$ angles of the $\mathrm{ImMe}_{2} \mathrm{CH}_{2}$ substituted BN and BNBN adducts are $162.57^{\circ}$ and $152.26^{\circ}$, respectively, and the C-B-N bond angles are $156.50^{\circ}$ and $156.32^{\circ}$ for the corresponding $\mathrm{Me}_{3} \mathrm{PCH}_{2}$ substituted analogues. In general, within the monoadducts, the $\mathrm{B}_{2} \mathrm{~N}_{2}$ and $\mathrm{B}_{3} \mathrm{~N}_{3}$ rings adopt planar geometries; the $\mathrm{B}_{3} \mathrm{~N}_{3}$ rings in $\mathrm{ImMe}_{2}$ and $\mathrm{ImMe}_{2} \mathrm{CH}_{2}$ are slightly puckered. The B-N bond lengths involving the donor-bound boron atoms in these $\mathrm{B}_{2} \mathrm{~N}_{2}$ and $\mathrm{B}_{3} \mathrm{~N}_{3}$ rings are each $c a$. $0.12 \AA$ longer than the remaining $\mathrm{B}-\mathrm{N}$ bonds involving donor-free, two coordinate boron centers. This bond lengthening implies an increase in $\mathrm{B}-\mathrm{N} \pi$-interactions and/or enhanced ionic contribution to the $\mathrm{B}-\mathrm{N} \sigma$-bonds. Within the $\mathrm{ImMe}_{2}$ monoadduct series, the formally dative C-B linkages range from $1.510 \AA$ in the terminal adduct $\mathrm{ImMe}_{2} \cdot \mathrm{BNBN}$ to elongated values of 1.560 and $1.612 \AA$ in the heterocyclic $\mathrm{B}_{2} \mathrm{~N}_{2}$ and $\mathrm{B}_{3} \mathrm{~N}_{3}$ adducts. For comparison, the $\mathrm{C}-\mathrm{B}$ bond length in the coordinatively saturated amino-borane adduct $\mathrm{IPr} \cdot \mathrm{BH}_{2}-\mathrm{NHDipp}$
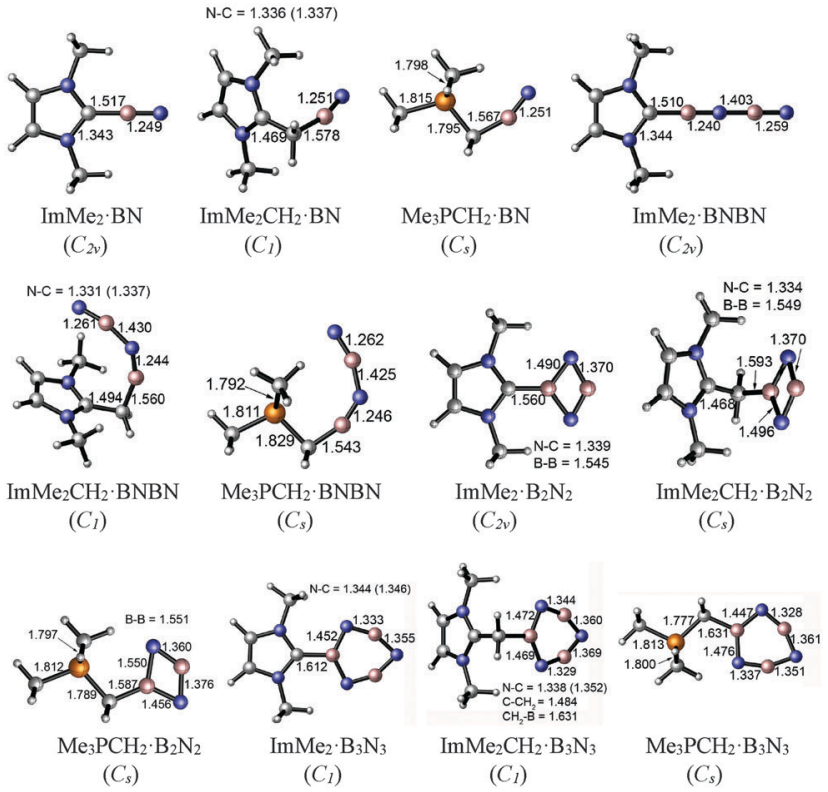

Fig. 2 M05-2X/cc-pVTZ optimized geometries including important bond lengths and corresponding symmetries of the mono-substituted adducts in the gas phase.

$\left(\mathrm{IPr}=\left[(\text { HCNDipp })_{2} \mathrm{C}:\right] ;\right.$ Dipp $\left.=2,6-{ }^{\mathrm{i}} \mathrm{Pr}_{2} \mathrm{C}_{6} \mathrm{H}_{3}\right)$ was determined to be $1.627(4) \AA{ }^{81}$ while in the diboryne adduct IPr. $\mathrm{B} \equiv \mathrm{B} \cdot \mathrm{IPr}$ this bond length is 1.491(4) $\AA$ (avg.). ${ }^{7}$ In general the computed C-B bonds in the $\mathrm{ImMe}_{2}$ adducts were shorter by $c a$. 0.02 to $0.05 \AA$ compared to the corresponding $\mathrm{ImMe}_{2} \mathrm{CH}_{2}$ and $\mathrm{Me}_{3} \mathrm{PCH}_{2}$ complexes; of note, it has been found that $\mathrm{N}$-heterocyclic carbenes are stronger $\sigma$-donors than their $\mathrm{N}$-heterocyclic olefin counterparts (such as $\mathrm{IPrCH}_{2}$ ) ${ }^{62}$ The coordination of the $\mathrm{Me}_{3} \mathrm{PCH}_{2}$ units to boron leads to a large increase in the ylidic $\mathrm{P}-\mathrm{C}$ bond length from $1.672 \AA$ in the free ligand to bond length values as long as $1.829 \AA$ in $\mathrm{Me}_{3} \mathrm{PCH}_{2} \cdot \mathrm{BNBN}$. This observation could be traced to a reduction of $\mathrm{H}_{2} \mathrm{C} \rightarrow \mathrm{P}-\mathrm{C}\left(\sigma^{*}\right)$ hyperconjugative interactions $\mathrm{s}^{31,82}$ in $\mathrm{Me}_{3} \mathrm{PCH}_{2}$ as the terminal $\mathrm{CH}_{2}$ unit participates in coordination to boron. The same phenomenon can be observed in the case of the $\mathrm{ImMe}_{2} \mathrm{CH}_{2}$ adducts: the terminal $\mathrm{C}-\mathrm{C}$ bond length increases from $1.353 \AA$ in the free ligand to $1.494 \AA$ in the BNBN substituted adduct $\mathrm{ImMe}_{2} \mathrm{CH}_{2} \cdot \mathrm{BNBN}$. For the isolated $\mathrm{ImMe}_{2} \mathrm{CH}_{2}$ and $\mathrm{Me}_{3} \mathrm{PCH}_{2}$ ligands, the $\mathrm{P}-\mathrm{C}$ and $\mathrm{C}-\mathrm{C}$ bonds have Wiberg bond indices (WBIs) of 1.328 and 1.613, respectively, based on NBO analyses, see section 3.3. These are reduced to 0.906-1.046 and 1.026-1.284, respectively, upon binding of the $(\mathrm{BN})_{x}$ units reflecting the loss of double bond character, and, hence, the corresponding bond elongation.

The M05-2X/cc-pVTZ optimized geometries of the di- and tri-substituted adducts (LB.(BN) $)_{n}, n=2$ and 3) are depicted in Fig. 3. In general, addition of a second equivalent of Lewis base to the $\mathrm{B}_{2} \mathrm{~N}_{2}$ and $\mathrm{B}_{3} \mathrm{~N}_{3}$ units leads to elongation of the average $\mathrm{C}-\mathrm{B}$ bond length. The $\mathrm{C}-\mathrm{B}$ bonds increase in length by $c a$. 0.06$0.09 \AA$ for the $\mathrm{B}_{2} \mathrm{~N}_{2}$ rings, while a more modest increase of $c a$. 0.01 to $0.04 \AA$ was noted upon binding two donors to a $\mathrm{B}_{3} \mathrm{~N}_{3}$ unit. Despite the planar nature of the $\mathrm{B}_{2} \mathrm{~N}_{2}$ rings, the intraring $\mathrm{B}-\mathrm{N}$ distances within the bis-adducts $\left(\mathrm{ImMe}_{2}\right)_{2} \cdot \mathrm{B}_{2} \mathrm{~N}_{2},\left(\mathrm{ImMe}_{2} \mathrm{CH}_{2}\right)_{2} \cdot \mathrm{B}_{2} \mathrm{~N}_{2}$, 

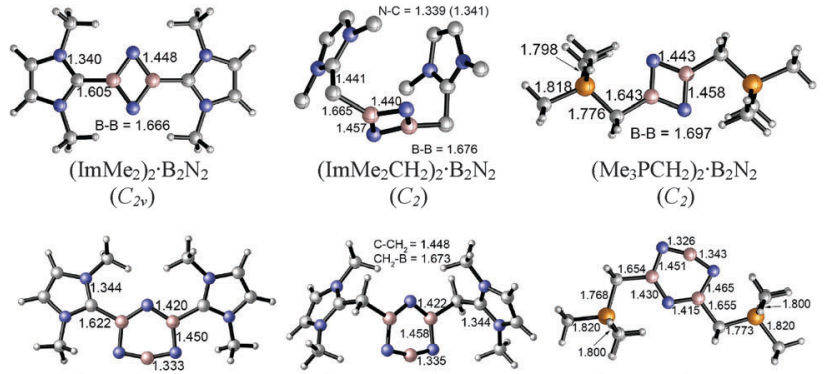

$(\operatorname{ImMe})_{2} \cdot \mathrm{B}_{3} \mathrm{~N}_{3}$

$\left(C_{2}\right)$

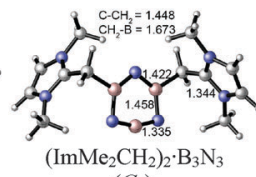

$\left(C_{2}\right)$

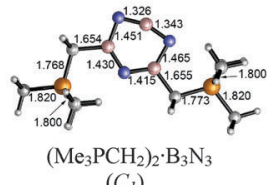

$\left(C_{I}\right)$

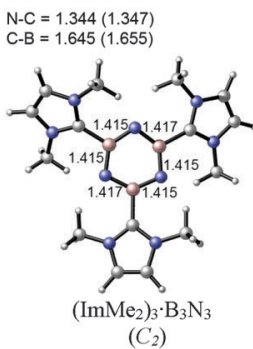

$\mathrm{N}-\mathrm{C}=1.342-1.345$

$\mathrm{C}-\mathrm{CH}_{2}=1.429-1.438$

$\mathrm{CH}_{2}-\mathrm{B}=1.717-1.732$

$\mathrm{CH}_{3}-\mathrm{P}=1.799-1.821$

$\mathrm{CH}_{2}=1.687-1702$

$\mathrm{CH}_{2}-\mathrm{B}=1.687-1.702$
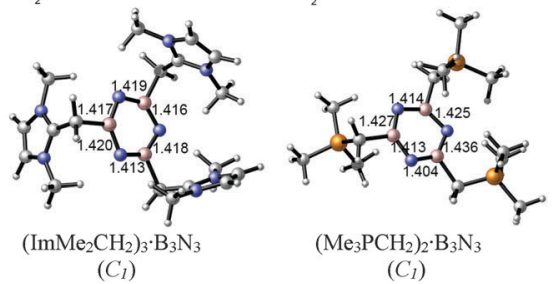

$\left(C_{1}\right)$

Fig. 3 M05-2X/cc-pVTZ optimized geometries and symmetries of the di- and tri-substituted adducts in the gas phase $(\mathrm{C}-\mathrm{H}$ bonds are omitted in the case of $\left(\mathrm{ImMe}_{2} \mathrm{CH}_{2}\right)_{2} \cdot \mathrm{B}_{2} \mathrm{~N}_{2}$ for clarity).

and $\left(\mathrm{Me}_{3} \mathrm{PCH}_{2}\right)_{2} \cdot \mathrm{B}_{2} \mathrm{~N}_{2}$ all lie within a narrow range of 1.440 to $1.448 \AA$ and suggest the absence of strong $\mathrm{B}-\mathrm{N} \pi$-bonding. To compare, iminoboranes $\left(\mathrm{RB} \equiv \mathrm{NR}^{\prime}\right)$ have $\mathrm{B}-\mathrm{N}$ triple bond lengths in the range of 1.23 to $1.26 \AA{ }^{83-86}$ while the diborylamide anion $\left[\mathrm{Mes}_{2} \mathrm{~B}=\mathrm{N}=\mathrm{BMes}_{2}\right]^{-}\left(\mathrm{Mes}=2,4,6-\mathrm{Me}_{3} \mathrm{C}_{6} \mathrm{H}_{2}\right)$, which has significant $\mathrm{B}=\mathrm{N}$ double bond character, has $\mathrm{B}-\mathrm{N}$ lengths of 1.343(5) and 1.348(5) $\AA^{8} .{ }^{87}$ The central $\mathrm{B}_{3} \mathrm{~N}_{3}$ units in each complex adopt nearly planar arrangements with intraring $\mathrm{B}-\mathrm{N}$ bond lengths that are typical for short B-N single bonds (1.404 to $1.436 \AA$ ). Each of the coordinative $\mathrm{C}-\mathrm{B}$ distances are slightly longer in $\left(\mathrm{ImMe}_{2}\right)_{3} \cdot \mathrm{B}_{3} \mathrm{~N}_{3}$ (1.645 to $1.655 \AA$ ) in relation to the values found in the bisadduct $\left(\operatorname{ImMe}_{2}\right)_{2} \cdot \mathrm{B}_{3} \mathrm{~N}_{3}(1.622 \AA)$. The ylide-bound tris adducts $\left(\mathrm{Me}_{3} \mathrm{PCH}_{2}\right)_{3} \cdot \mathrm{B}_{3} \mathrm{~N}_{3}$ and $\left(\mathrm{ImMe}_{2} \mathrm{CH}_{2}\right)_{3} \cdot \mathrm{B}_{3} \mathrm{~N}_{3}$ feature very long $\mathrm{C}-\mathrm{B}$ bonds of 1.717-1.732 and 1.687-1.702 $\AA$, respectively, suggesting that these species would have reduced stability.

Very recently, Tai and Nguyen have studied the stability of $\left(\operatorname{ImMe}_{2} \cdot \mathrm{B}\right)_{n}(n=1-6)$ adducts using quantum mechanical computations with the B3LYP method. ${ }^{88}$ They attributed the stability of these systems to the degree of $\pi$ conjugation and aromatic character within the core $\mathrm{B}_{n}(n=3-6)$ rings. In order to probe the aromaticity in the $(\mathrm{BN})_{x}$ rings, NICS analyses of the free (singlet) $\mathrm{B}_{2} \mathrm{~N}_{2}$ and $\mathrm{B}_{3} \mathrm{~N}_{3}$ molecules as well as their adducts were performed using the GIAO method at the M05-2X/cc-pVTZ level of theory. The NICS results were compared to the corresponding values determined at the same level of theory for well known aromatic benzene and anti-aromatic cyclobutadiene molecules (Table S1, ESI $\dagger$ ) to examine changes in aromaticity upon binding of Lewis bases. NICS data are sensitive to the position at which they are evaluated and to interference from other parts of the molecule, especially for non-planar compounds. ${ }^{23}$ The changes in aromaticity/anti-aromaticity are discussed in terms of NICS $(1.00)_{z z}$ values, see Table S1, ESI $\dagger$ for complete NICS data.

Interestingly, NICS $(1.00)_{z z}$ values show aromatic character for the free $\mathrm{B}_{2} \mathrm{~N}_{2}$ and $\mathrm{B}_{3} \mathrm{~N}_{3}$ molecules $(-15.12$ and $-6.51 \mathrm{ppm}$, respectively, compared to $-31.06 \mathrm{ppm}$ for benzene). However, the free $\mathrm{B}_{2} \mathrm{~N}_{2}$ loses aromatic character upon binding of one $\mathrm{LB}$ ligand (i.e., NICS $(1.00)_{z z}$ values of $+2.55,+8.46$, and $+8.60 \mathrm{ppm}$ for $\mathrm{B}_{2} \mathrm{~N}_{2}$ complexed with $\mathrm{Me}_{3} \mathrm{PCH}_{2}, \mathrm{ImMe}_{2}$, and $\operatorname{ImMe}_{2} \mathrm{CH}_{2}$, respectively). For the doubly-bound adducts, $(\mathrm{LB})_{2} \cdot \mathrm{B}_{2} \mathrm{~N}_{2}$, the $\mathrm{B}_{2} \mathrm{~N}_{2}$ unit becomes significantly anti-aromatic: $+12.62,+13.94$, and +9.04 ppm for the $\mathrm{Me}_{3} \mathrm{PCH}_{2}, \mathrm{ImMe}_{2}$, and $\mathrm{ImMe}_{2} \mathrm{CH}_{2}$ adducts, respectively (see Table S1, ESI $\dagger$ ). On the other hand, $\mathrm{B}_{3} \mathrm{~N}_{3}$ remains moderately aromatic upon attachment of 1,2 , or 3 equivalents of Lewis base. The NICS $(1.00)_{z z}$ decrease upon attaching two Lewis bases to the $\mathrm{B}_{3} \mathrm{~N}_{3}$ ring with values of -8.55 and $-3.19 \mathrm{ppm}$ for ImMe $\mathrm{I}_{2}$ and $\mathrm{ImMe}_{2} \mathrm{CH}_{2}$ ligands, respectively, but slightly increases from $-6.95 \mathrm{ppm}$ to $-6.39 \mathrm{ppm}$ upon attaching the second $\mathrm{Me}_{3} \mathrm{PCH}_{2}$ ligand. For the case of the three LB bound adducts, the NICS $(1.00)_{z z}$ values all increase $(-2$ to $-3 \mathrm{ppm}$ ) upon attachment of the third ligand (Table S1, ESI $\dagger$ ).

\subsection{Energies of the Lewis base (LB) bound LB. $(\mathrm{BN})_{n}(n=1-3)$ adducts}

The total stabilization energies and Gibbs free energies of the $(\mathrm{BN})_{n}(n=1-3)$ molecules upon complexation with the three Lewis bases were computed using the M05-2X/cc-pVTZ level of theory and the results are summarized in Table 1 . The sequential stabilization energies, $\Delta E_{\text {seq. }},(\Delta E+\mathrm{ZPE})_{\text {seq. }}$, and $\Delta G_{\text {seq. }}^{\circ}$, which take into account the impact of adding one additional Lewis base to the existing $(\mathrm{LB})_{x} \cdot \mathrm{B}_{2} \mathrm{~N}_{2}$ and $(\mathrm{LB})_{x} \cdot \mathrm{B}_{3} \mathrm{~N}_{3}(x=0-2)$ complexes were also evaluated. Notably, in two separate articles, Jones, Frenking and co-workers have studied the $\mathrm{ImMe}_{2} \mathrm{MM}^{-}$and phosphine-bound Group 13 element complexes along with their possible applications for hydrogen storage. ${ }^{89,90}$ More specifically, they found that the Gibbs free energies of -29.8 and $-45.8 \mathrm{kcal} \mathrm{mol}^{-1}$ for the $\mathrm{Me}_{3} \mathrm{P}$ and $\mathrm{ImMe}_{2}$ bound $\mathrm{BH}_{3}$ adducts, respectively, at the RI-BP86/def2TZVPP level of theory; which is very close to the $-46.9 \mathrm{kcal} \mathrm{mol}^{-1}$ computed for the latter complex, ImMe ${ }_{2} \cdot \mathrm{BH}_{3}$, at the M06-2X/ccpVDZ level of theory. ${ }^{91}$ In another recent study, Sarmah et al. examined complexes of normal and abnormal N-heterocyclic carbenes with Group 13 element based Lewis acids $\left(\mathrm{EX}_{3} ; \mathrm{E}=\mathrm{B}\right.$, $\mathrm{Al}, \mathrm{Ga} ; \mathrm{X}=\mathrm{H}, \mathrm{F}, \mathrm{Cl}, \mathrm{OH}, \mathrm{NH}_{2}, \mathrm{CH}_{3}, \mathrm{CF}_{3}$ ) and performed corresponding NBO and AIM analyses of the adducts. ${ }^{92}$ They computed a complexation energy of $-49.2 \mathrm{kcal} \mathrm{mol}^{-1}$ at the $\mathrm{B} 3 \mathrm{LYP} / 6-31+\mathrm{G}^{*}$ level of theory for the $\mathrm{ImMe}_{2} \cdot \mathrm{BH}_{3}$ adduct which is close to the values found previously by Frenking, Jones and co-workers ${ }^{89,90}$ as well as Brown and coworkers. ${ }^{91}$ The complexation (stabilization) energy associated with the formation of our mono-substituted $(\mathrm{BN})_{n}(n=1-3)$ adducts was computed to be greater than $-100 \mathrm{kcal} \mathrm{mol}^{-1}$ for all species except the $\mathrm{B}_{3} \mathrm{~N}_{3}$ adducts, where zero-point corrected energies $(\Delta E+\mathrm{ZPE})$ are in the range of -57.4 to $-69.7 \mathrm{kcal} \mathrm{mol}^{-1}$. The ZPE correction to the electronic energies changes the value of $\Delta E$ by $\sim 4-10 \mathrm{kcal} \mathrm{mol}^{-1}$. The Gibbs free energy differences are also lower than the ZPE corrected values by $\sim 10-40 \mathrm{kcal} \mathrm{mol}^{-1}$. For the sake of brevity and consistency, the Gibbs free energy differences will be discussed throughout the text. We will comment on the nature of the formed 
Table 1 Computed total $^{a}$ and sequential ${ }^{b}$ stabilization energies (in $\mathrm{kcal} \mathrm{mol}^{-1}$ ), with ZPE $(\Delta E+\mathrm{ZPE})$ and without ZPE $(\Delta E)$, and free energies $\left(\Delta G^{\circ}\right)$ at the M05-2X/cc-pVTZ level of theory

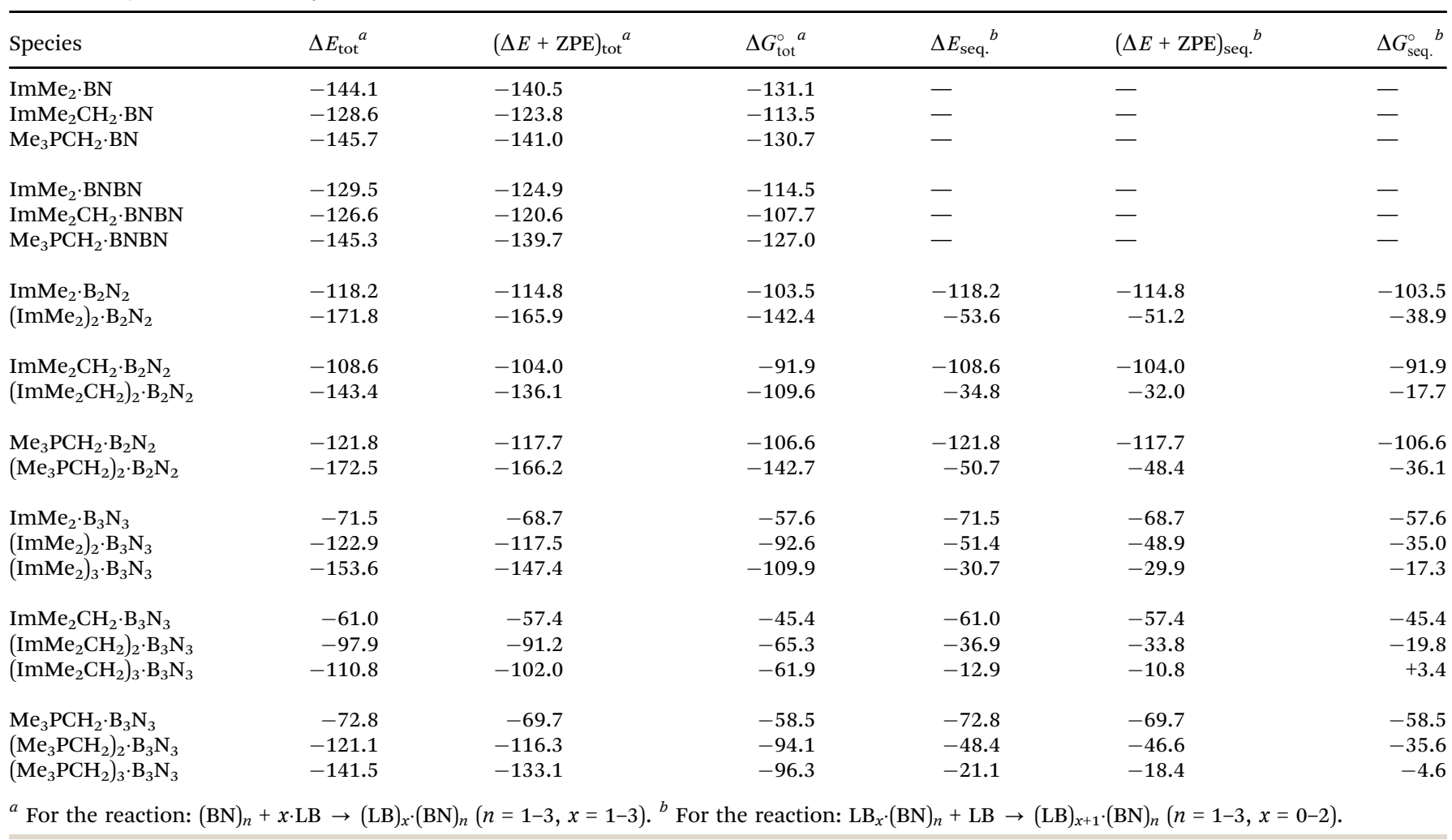

carbene-boron bonds including their degrees of ionic/covalent character based on EDA as well as NBO/AIM analyses. The gap between the highest occupied molecular orbital (HOMO) and the lowest unoccupied molecular orbital (LUMO) increases for all of the boron nitride species upon binding of the carbon-based ligands; the exceptions to this trend are the $\mathrm{B}_{3} \mathrm{~N}_{3}$ adducts (Fig. S3, ESI $\dagger$ ). For $\mathrm{B}_{3} \mathrm{~N}_{3}$, the ImMe $\mathrm{Im}_{2}$ and $\mathrm{ImMe}_{2} \mathrm{CH}_{2}$ bound adducts exhibit a modest decrease in the HOMO-LUMO gap upon binding the first ligand (for $\mathrm{Me}_{3} \mathrm{PCH}_{2}$ there is a small increase of $\approx 0.3 \mathrm{eV}$ ) and then for all ligands, there is a larger $(\approx 1 \mathrm{eV})$ decrease upon binding the second and third ligands.

The free energies associated with the sequential addition of Lewis base equivalents to molecular $\mathrm{B}_{2} \mathrm{~N}_{2}$ and $\mathrm{B}_{3} \mathrm{~N}_{3}$ molecules $\Delta G_{\text {seq. }}^{\circ}$ follow the general trend that it becomes increasingly less favorable to bind multiple donors to these rings (Fig. 4).

This effect can be explained by a decrease in Lewis acidity of the $(\mathrm{BN})_{n}$ rings as electron density is being donated from the carbonbased ligands; this phenomenon can be easily observed from the gradual destabilization of the LUMO energy levels of the $\mathrm{B}_{2} \mathrm{~N}_{2}$ and $\mathrm{B}_{3} \mathrm{~N}_{3}$ rings after addition of the Lewis bases (Fig. S3, ESI $\dagger$ ). Overall, the binding of subsequent equivalents of Lewis base to the $\mathrm{BN}$ rings is exergonic, however, a slightly disfavoured binding event was computed for the formation of the tris adduct $\left(\mathrm{ImMe}_{2} \mathrm{CH}_{2}\right)_{3}$. $\mathrm{B}_{3} \mathrm{~N}_{3}\left(+3.4 \mathrm{kcal} \mathrm{mol}^{-1}\right)$, placing this species on the cusp of stability.

\subsection{Bonding properties through NBO and AIM analyses}

NBO and AIM computations were performed on all $(\mathrm{BN})_{n}$ species including their free and as well as their ligand bound

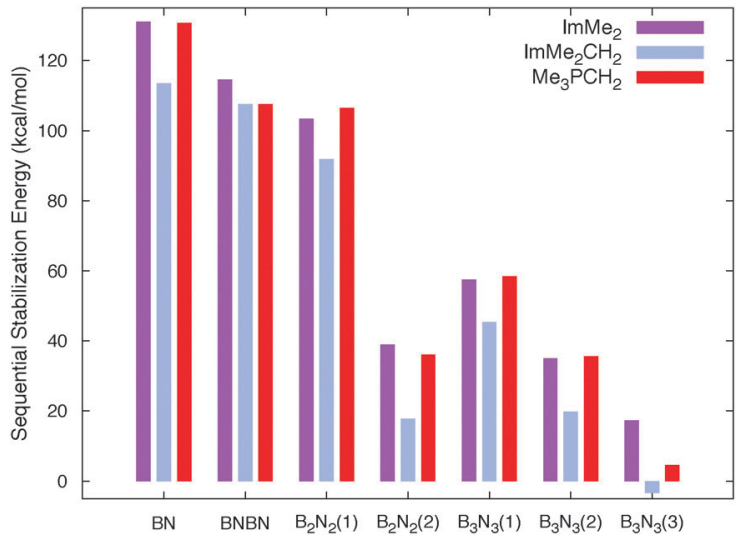

Fig. 4 The absolute values of the computed M05-2X/cc-pVTZ sequential Gibbs free stabilization energies (in $\mathrm{kcal} \mathrm{mol}^{-1}$ ) of all the adducts studied in this work. Numbers in parenthesis denote the number of Lewis base molecules attached to the $B_{2} N_{2}$ and $B_{3} N_{3}$ molecules. See Table 1 for the values.

forms at the M05-2X/cc-pVTZ level of theory (see Table 2; for the NBO and AIM analyses of the di- and tri-substituted compounds see Tables S2-S9 and Fig. S2, ESI, $\dagger$ respectively). The computed NBO atomic charges of the boron atoms show a significant decrease $\left(0.5\right.$ to $\left.0.6 \mathrm{e}^{-}\right)$upon attachment of the Lewis bases. However, the change in charge of the bonding carbon atom upon complexation is much more modest ca. 0.1 to 0.2 (Table 2 and Table S2, ESI $\dagger$ ). The charge transfer to the boron center is highest for the $\mathrm{ImMe}_{2}$ and lowest for the $\mathrm{Me}_{3} \mathrm{PCH}_{2}$ substituted $\mathrm{BN}$ and BNBN adducts. For both $\mathrm{B}_{2} \mathrm{~N}_{2}$ 
Table 2 Selected NBO atomic charges of the carbene carbon and boron atoms $\left(q_{C}\right.$ and $\left.q_{B}\right)$ along with the total charge of the acceptor molecules $\left(q_{L A}\right)$, Wiberg bond indices (WBI) of the $\mathrm{C}-\mathrm{B}$ and $\mathrm{B}-\mathrm{N}$ bonds, and the electron density $(\rho)$ and energy density at the bond critical points $\left(\mathrm{H}_{(\mathrm{C}-\mathrm{B})}\right.$ and $\left.\mathrm{H}_{(\mathrm{B}-\mathrm{N})}\right)$ for all the mono-substituted species at the M05-2X/cc-pVTZ level of theory. B-N values refer to bonds adjacent to the carbene carbon atom. Values in parentheses correspond to two different $\mathrm{B}-\mathrm{N}$ bonds connected to the carbene carbon atom

\begin{tabular}{llllllllll}
\hline Species & $q_{\mathrm{C}}$ & $q_{\mathrm{B}}$ & $q_{\mathrm{LA}}$ & $\mathrm{WBI}_{\mathrm{C}-\mathrm{B}}$ & $\mathrm{WBI}_{\mathrm{B}-\mathrm{N}}$ & $\rho\left(r_{\mathrm{C}-\mathrm{B}}\right)$ & $\mathrm{H}\left(r_{\mathrm{C}-\mathrm{B}}\right)$ & $\rho\left(r_{\mathrm{B}-\mathrm{N}}\right)$ & $\mathrm{H}\left(r_{\mathrm{B}-\mathrm{N}}\right)$ \\
\hline $\mathrm{ImMe}_{2} \cdot \mathrm{BN}$ & +0.203 & +0.230 & -0.524 & 0.944 & 2.622 & 0.179 & -0.175 & 0.300 & -0.324 \\
$\mathrm{ImMe}_{2} \mathrm{CH}_{2} \cdot \mathrm{BN}$ & -0.821 & +0.367 & -0.551 & 0.772 & 2.656 & 0.163 & -0.158 & 0.298 & -0.324 \\
$\mathrm{Me}_{3} \mathrm{PCH}_{2} \cdot \mathrm{BN}$ & -1.046 & +0.382 & -0.565 & 0.872 & 2.604 & 0.166 & -0.162 & 0.299 & -0.325 \\
& & & & & & & & \\
$\mathrm{ImMe}_{2} \cdot \mathrm{BNBN}$ & +0.140 & +0.608 & -0.553 & 0.966 & 2.062 & 0.189 & -0.193 & 0.290 & -0.295 \\
$\mathrm{ImMe}_{2} \mathrm{CH}_{2} \cdot \mathrm{BNBN}$ & -0.794 & +0.838 & -0.628 & 0.898 & 2.018 & 0.180 & -0.184 & 0.298 & -0.320 \\
$\mathrm{Me}_{3} \mathrm{PCH}_{2} \cdot \mathrm{BNBN}$ & -1.075 & +0.858 & -0.603 & 0.931 & 1.997 & 0.185 & -0.191 & 0.298 & -0.322 \\
$\mathrm{ImMe}_{2} \cdot \mathrm{B}_{2} \mathrm{~N}_{2}$ & & & & & & & \\
$\mathrm{ImMe}_{2} \mathrm{CH}_{2} \cdot \mathrm{B}_{2} \mathrm{~N}_{2}$ & -0.73 & +0.654 & -0.651 & 0.861 & 0.998 & 0.171 & -0.170 & 0.192 & -0.199 \\
$\mathrm{Me}_{3} \mathrm{PCH}_{2} \cdot \mathrm{B}_{2} \mathrm{~N}_{2}$ & -1.037 & +0.783 & -0.622 & 0.801 & 0.969 & 0.166 & -0.168 & 0.189 \\
$\mathrm{ImMe}_{2} \cdot \mathrm{B}_{3} \mathrm{~N}_{3}$ & +0.251 & +0.749 & -0.622 & 0.840 & $1.096(0.846)$ & 0.167 & -0.168 & $0.204(0.172)$ & $-0.214(-0.171)$ \\
$\mathrm{ImMe}_{2} \mathrm{CH}_{2} \cdot \mathrm{B}_{3} \mathrm{~N}_{3}$ & -0.763 & +0.863 & -0.578 & 0.749 & $1.022(1.096)$ & 0.157 & -0.157 & $0.184(0.185)$ & $-0.183(-0.182)$ \\
$\mathrm{Me}_{3} \mathrm{PCH}_{2} \cdot \mathrm{B}_{3} \mathrm{~N}_{3}$ & -1.062 & +0.690 & -0.572 & 0.689 & $1.145(1.143)$ & 0.154 & -0.152 & $0.194(0.255)$ & $-0.195(-0.179)$
\end{tabular}

and $\mathrm{B}_{3} \mathrm{~N}_{3}$ adducts, the highest charge transfer to the boron atom belongs to the $\mathrm{ImMe}_{2}$ and $\mathrm{Me}_{3} \mathrm{PCH}_{2}$ ligands, respectively, but the lowest to the $\mathrm{ImMe}_{2} \mathrm{CH}_{2}$ ligand (Table 2). Interestingly, the NBO analysis does not show a significant charge difference for the nitrogen atom attached to the boron center in the LB.BN adducts compared to the isolated species (Tables S2 and S3, ESI $\dagger)$. On the other hand, in LB-BNBN adducts, the terminal nitrogen gains about $0.4-0.8$ electrons and the central $\mathrm{N}$ atom loses about $0.2-0.4$ electrons relative to the free species. For $\mathrm{B}_{2} \mathrm{~N}_{2}$, the boron loses 0.1-0.2 electrons, while the nitrogen shows a 0.4 electron gain upon complexation; the changes in partial charges of $\mathrm{B}$ and $\mathrm{N}$ in $\mathrm{B}_{3} \mathrm{~N}_{3}$ are very modest $\left(0.1-0.2 \mathrm{e}^{-}\right)$. Therefore, there is stronger electronic communication in the BNBN complexes compared to the other adducts. Also, the Wiberg bond index (WBI) shows the following trend for all the C-B bonds in the mono-substituted adducts: LB.BNBN > LB.BN $>$ LB. $B_{2} \mathrm{~N}_{2}>$ LB. $B_{3} \mathrm{~N}_{3}$; a rather similar trend can be observed for the AIM electron densities $(\rho)$ of these bonds
(Table 2). On the other hand, the trend of the WBI for the

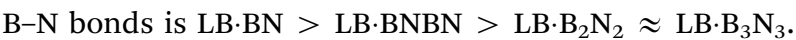

Analysis of the energy density $(\mathrm{H}(r))$ at the $\mathrm{C}-\mathrm{B}$ and $\mathrm{B}-\mathrm{N}$ bond critical points shows that all of these bonds are predominantly covalent in character (i.e., negative values for $\mathrm{H}_{(\mathrm{C}-\mathrm{B})}$ and $\left.\mathrm{H}_{(\mathrm{B}-\mathrm{N})}\right)$. This data agrees well with the EDA-NOCV results which will be discussed later and points to the existence of covalent bonding between the carbon donors and boron acceptors, which is accompanied by $\pi$-backbonding in these systems as previously noted in $\mathrm{LB} \cdot \mathrm{BX}_{3}(\mathrm{X}=\mathrm{H}, \mathrm{F}, \mathrm{Cl})$ adducts. ${ }^{93,94}$ The computed value of the electron density $(\rho)$ for the C-B bonds also shows that its strength decreases in the order of $\mathrm{ImMe}_{2}>$ $\mathrm{Me}_{3} \mathrm{PCH}_{2}>\mathrm{ImMe}_{2} \mathrm{CH}_{2}$ in the case of the BN, BNBN, and the $\mathrm{B}_{2} \mathrm{~N}_{2}$ adducts. For the mono-substituted $\mathrm{B}_{3} \mathrm{~N}_{3}$ adducts, the trend in $\rho$ is $\mathrm{ImMe}_{2} \mathrm{CH}_{2}>\mathrm{ImMe}_{2} \approx \mathrm{Me}_{3} \mathrm{PCH}_{2}$ (Table 2) although the differences in $\rho$ are very small $\left(<0.003 \mathrm{e}^{-}\right)$. The $\rho$ values for the B-N bonds in each of the adducts increase from $0.185 \mathrm{e}^{-}$to $0.300 \mathrm{e}^{-}$on going from the $\mathrm{B}_{3} \mathrm{~N}_{3}$ adducts to the $\mathrm{BN}$

Table 3 Computed EDA-NOCV components (in $\mathrm{kcal} \mathrm{mol}^{-1}$ ) for the $\mathrm{C}-\mathrm{B}$ bonds of the $\mathrm{BN}$ and $\mathrm{B}_{3} \mathrm{~N}_{3}$ substituted systems at the BP86/TZ2P level of theory. The $\mathrm{C}-\mathrm{B}$ bond lengths $\left(R\right.$, in $\AA$ ) are also provided for all the complexes ${ }^{a}$

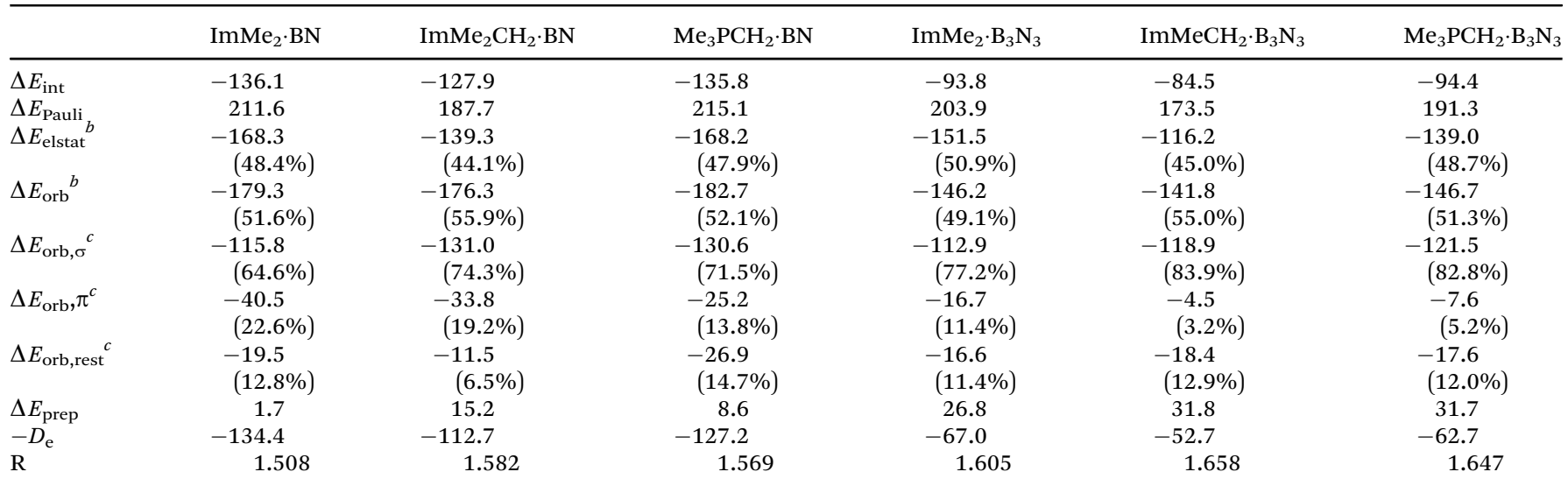

${ }^{a}$ For deformation densities see Fig. 5. ${ }^{b}$ Percentage contributions to the total attractive interactions $\left(\Delta E_{\text {elstat }}+\Delta E_{\text {orb }}\right)$ provided in parenthesis.

${ }^{c}$ Percentage contributions to the total orbital interactions $\Delta E_{\text {orb }}$ provided in parenthesis. 
adducts, in line with the corresponding increase in WBI values for these species. From the optimized geometries, we found that the $\mathrm{C}-\mathrm{B}$ bond length increases upon substituting more Lewis bases. AIM data are in agreement with the geometries as, for example, the $\rho$ value for this bond decreases from $0.154 \mathrm{e}^{-}$ in the $\operatorname{ImMe}_{2} \cdot \mathrm{B}_{3} \mathrm{~N}_{3}$ complex to $0.136-0.139 \mathrm{e}^{-}$in $\left(\operatorname{ImMe}_{2}\right)_{3} \cdot \mathrm{B}_{3} \mathrm{~N}_{3}$ while the $\mathrm{C}-\mathrm{B}$ bond length increases from $1.612 \AA$ to $\sim 1.650 \AA$ (Fig. S2, ESI, $\dagger$ and Fig. 2 and 3). This trend mirrors the variation in stabilization energies, and indicate that the interaction between the Lewis base and the boron atoms becomes weaker in the presence of added equivalents of donor. The $\rho$ values of the C-B bonds for $\left(\mathrm{ImMe}_{2} \mathrm{CH}_{2}\right)_{n} \cdot \mathrm{B}_{3} \mathrm{~N}_{3}$ and $\left(\mathrm{Me}_{3} \mathrm{PCH}_{2}\right)_{n} \cdot \mathrm{B}_{3} \mathrm{~N}_{3}$ also decrease by going from mono- to tri-substituted adducts: from $0.157 \mathrm{e}^{-}$to $0.120 \mathrm{e}^{-}$and from $0.154 \mathrm{e}^{-}$to $0.127 \mathrm{e}^{-}$, respectively (Fig. S2, ESI $\dagger$ ); a trend reflected in the corresponding $\mathrm{C}-\mathrm{B}$ bond length.

\subsection{Energy decomposition analysis (EDA-NOCV)}

To understand the nature of the bonding between different Lewis bases and the cyclic and acyclic boron nitride oligomers (LB·(BN $\left.)_{n}, n=1-3\right)$, EDA-NOCV computations were performed using the GGA BP86 functional and the TZ2P basis set (Table 3). For brevity, we only focus on the most stabilized and least stabilized boron nitride species, i.e., LB.BN and $\mathrm{LB} \cdot \mathrm{B}_{3} \mathrm{~N}_{3}$, respectively. The order of bond dissociation energies $\left(D_{\mathrm{e}}\right)$ for the different Lewis bases follows the series $\mathrm{ImMe}_{2}>\mathrm{Me}_{3} \mathrm{PCH}_{2}$ $>\mathrm{ImMe}_{2} \mathrm{CH}_{2}$. More specifically, the C-B bonds in the ImMe substituted adducts are 4.3-21.7 $\mathrm{kcal} \mathrm{mol}^{-1}$ stronger than their $\mathrm{Me}_{3} \mathrm{PCH}_{2}$ and $\mathrm{ImMe}_{2} \mathrm{CH}_{2}$ analogues. For a given boron nitride adduct, there is a clear correlation between $\mathrm{C}-\mathrm{B}$ bond length on one hand and bond dissociation energy and Pauli repulsion values on the other hand (Table 3).

The percentage contribution of the electrostatic attraction $\left(\Delta E_{\text {elstat }}\right)$ and orbital interaction $\left(\Delta E_{\text {orb }}\right)$ terms to the total attractive energies are also provided in Table 3 . Overall, the orbital interaction makes a significant contribution to the total attractive energy (more than 50\%) in all complexes except $\operatorname{ImMe}_{2} \cdot \mathrm{B}_{3} \mathrm{~N}_{3}$ where it is $49.1 \%$. This high contribution indicates that $\mathrm{C}-\mathrm{B}$ bonds retain substantial covalent character which is in agreement with our NBO/AIM results discussed above. The percentage contributions of the $\sigma$ and $\pi$ orbitals to the total orbital interaction are shown in Table 3 while the relevant deformation densities $(\Delta \rho)$ are depicted in Fig. 5. Notably, the ImMe $\mathrm{CH}_{2} \cdot \mathrm{B}_{3} \mathrm{~N}_{3}$ adduct shows the lowest $\pi$-contribution to the $\mathrm{C}-\mathrm{B}$ orbital interaction (3.2\%) amongst the compounds investigated, while in contrast, the $\mathrm{ImMe}_{2} \cdot \mathrm{BN}$ and $\mathrm{ImMe}_{2} \mathrm{CH}_{2} \cdot \mathrm{BN}$ adducts show the highest degree of $\pi$-character with $22.6 \%$ and $19.2 \%$ contributions, respectively. Thus from both Table 3 and Fig. 5 it is evident that $\pi$-backbonding between the boron nitride oligomers and the carbon-based ligands can be quite significant in some cases. The preparation energy $\left(\Delta E_{\text {prep }}\right)$, the difference between the fragment energies in their complexed and free geometries, is the lowest for the $\mathrm{ImMe}_{2} \cdot \mathrm{BN}$ while it is the highest for the $\operatorname{ImMe}_{2} \mathrm{CH}_{2} \cdot \mathrm{B}_{3} \mathrm{~N}_{3}$ adduct (Table 3 ).

Our $-D_{\mathrm{e}}$ values for the carbene-boron bonds are significantly more negative than the reported $-D_{\mathrm{e}}$ values for the $\mathrm{H}_{3} \mathrm{~B} \cdot \mathrm{NH}_{3}$

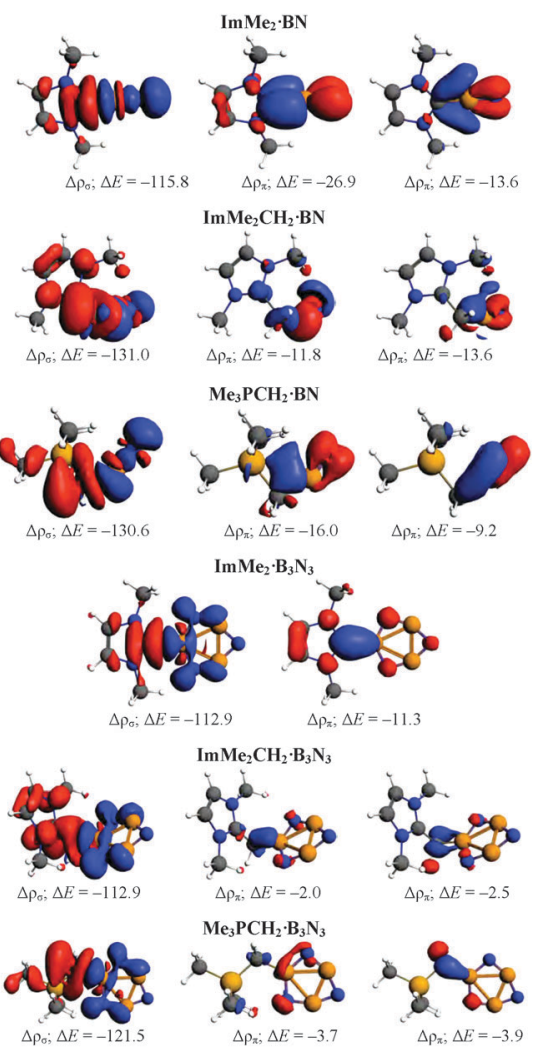

Fig. 5 Deformation densities $(\Delta \rho)$ associated with the most important pairwise orbital interactions for $\mathrm{C}-\mathrm{B}$ bond formation of different Lewis base substituted $\mathrm{BN}$ and $\mathrm{B}_{3} \mathrm{~N}_{3}$ adducts. The charge flow is from red $\rightarrow$ blue. Energies in $\mathrm{kcal} \mathrm{mol}^{-1}$ are also provided.

(-31.9 kcal $\left.\mathrm{mol}^{-1}\right)$ and $\mathrm{H}_{3} \mathrm{~B} \cdot \mathrm{NMe}_{3}\left(-36.2 \mathrm{kcal} \mathrm{mol}^{-1}\right)$ bonds computed at the BP86/TZ2P level of theory. ${ }^{93-95}$ Tonner and Frenking have shown that replacing ammonia with the $\mathrm{ImMe}_{2}$ ligand to form the $\mathrm{ImMe}_{2} \cdot \mathrm{BH}_{3}$ adduct changes the $-D_{\mathrm{e}}$ to $-57.9 \mathrm{kcal} \mathrm{mol}{ }^{-1}$ computed at the same level. ${ }^{96}$ Also, the amount

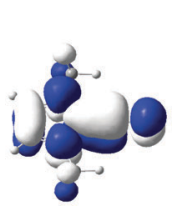

$B_{1}$ (LUMO) $-0.030$

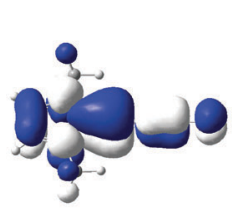

$B_{I}(\mathrm{LUMO})$ $-1.635$

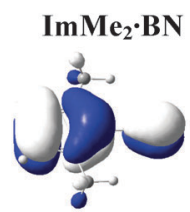

$B_{1}(\mathrm{HOMO})$ $-6.857$

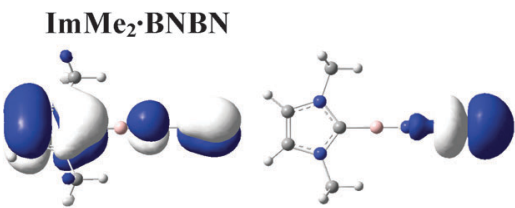

$B_{1}(\mathrm{HOMO})$ $-5.483$

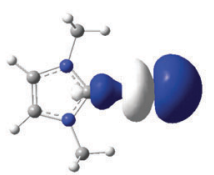

$A_{2}$ (HOMO-4) $-10.729$

$B_{2}(\mathrm{HOMO}-4)$ $-10.672$
Fig. 6 M05-2X/cc-pVTZ computed relevant MOs for the $\operatorname{ImMe} \mathrm{m}_{2} \cdot \mathrm{BN}$ and ImMe 2 BNBN substituted adducts in the gas phase. Symmetries as well as energies (in $\mathrm{eV}$ ) are also provided. 


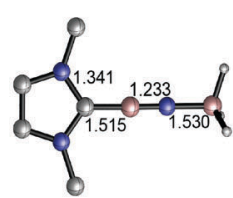

$\mathrm{ImMe}_{2} \cdot \mathrm{BN} \cdot \mathrm{BH}_{3}$ $-35.2$

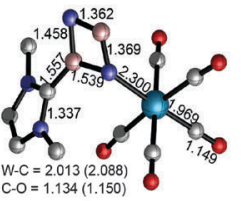

$\operatorname{ImMe}_{2} \cdot \mathrm{B}_{2} \mathrm{~N}_{2} \cdot \mathrm{W}(\mathrm{CO})_{5}$ $-38.1$

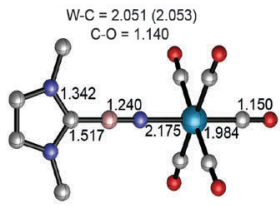

$\mathrm{ImMe}_{2} \cdot \mathrm{BN} \cdot \mathrm{W}(\mathrm{CO})_{5}$ $-46.6$

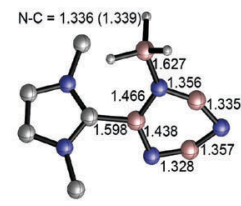

$\mathrm{ImMe}_{2} \cdot \mathrm{B}_{3} \mathrm{~N}_{3} \cdot \mathrm{BH}_{3}$-ortho $-21.3$

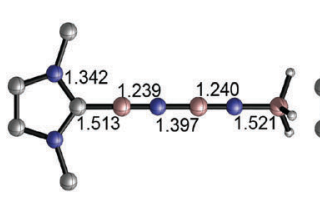

$\mathrm{ImMe}_{2} \cdot \mathrm{BNBN} \cdot \mathrm{BH}_{3}$ $-41.5$
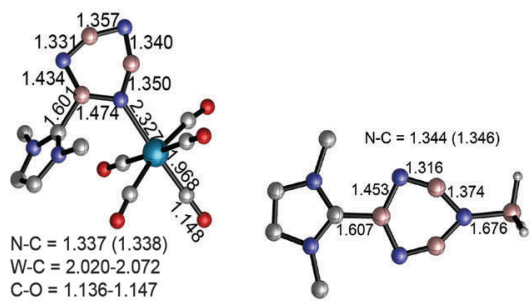

$\mathrm{ImMe}_{2} \cdot \mathrm{B}_{3} \mathrm{~N}_{3} \cdot \mathrm{BH}_{3}$-para $-10.7$

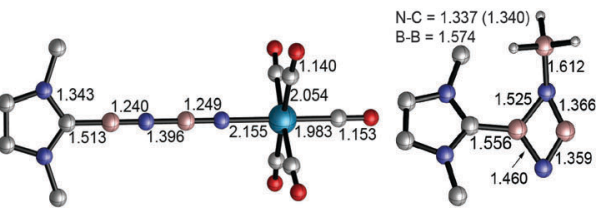

$\mathrm{ImMe}_{2} \cdot \mathrm{BNBN} \cdot \mathrm{W}(\mathrm{CO})_{5}$ $-55.6$

$\mathrm{ImMe}_{2} \cdot \mathrm{B}_{2} \mathrm{~N}_{2} \cdot \mathrm{BH}_{3}$ $-27.0$

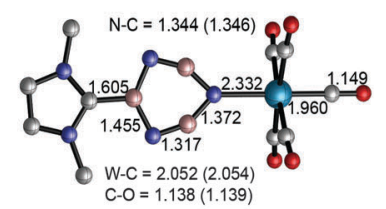

$\mathrm{ImMe}_{2} \cdot \mathrm{B}_{3} \mathrm{~N}_{3} \cdot \mathrm{W}(\mathrm{CO})_{5}$-para $-26.2$

Fig. 7 M05-2X/cc-pVTZ optimized geometries and Gibbs free energies of the $\mathrm{BH}_{3}$ and $\mathrm{W}(\mathrm{CO})_{5}$ substituted boron nitride adducts in the gas phase ( $\mathrm{C}-\mathrm{H}$ bonds are omitted for clarity).

of $\pi$-backbonding in $\mathrm{H}_{3} \mathrm{~B} \cdot \mathrm{NH}_{3}, \mathrm{Me}_{3} \mathrm{~N} \cdot \mathrm{BH}_{3}$, and $\mathrm{ImMe}_{2} \cdot \mathrm{BH}_{3}$ are $10.1 \%, 13.0 \%$, and $9.4 \%$, respectively. The values are comparable to each other for all these three systems and are close to the corresponding value for the $\mathrm{ImMe}_{2} \cdot \mathrm{B}_{3} \mathrm{~N}_{3}$ complex (Table 3).

\subsection{Stabilization through donor-acceptor interactions}

The HOMOs of both the ImMe $\cdot$ BN and $\mathrm{ImMe}_{2} \cdot \mathrm{BNBN}$ adducts have $\pi$ character localized on the (terminal) BN unit as well as on the ImMe $\mathrm{Mn}_{2}$ ring (Fig. 6). On the other hand, the HOMO-4 of both complexes shows a directional lone pair on the terminal nitrogen atom (with some mixing with a $\mathrm{B}-\mathrm{N} \sigma$ bond) ready to be captured by a Lewis acid (LA). Herein we consider the previously employed donor-acceptor approach for stabilizing highly reactive heavier Group 14 element dihydrides,${ }^{14}$ by using $\mathrm{BH}_{3}$ and $\mathrm{W}(\mathrm{CO})_{5}$ as Lewis acids (LA), and $\mathrm{ImMe}_{2}$ as a Lewis base. The M05-2X optimized Lewis acid/base bound $(\mathrm{BN})_{n}$ complexes as well as their complexation Gibbs free energies are shown in Fig. 7 (for a comparison between their electronic energies and Gibbs free energies see Table S12, ESI $\dagger$ ). The C-B bond lengths in the Lewis acid bound adducts $\mathrm{ImMe}_{2}$. BN.LA and $\mathrm{ImMe}_{2} \cdot \mathrm{BNBN} \cdot \mathrm{LA}\left(\mathrm{LA}=\mathrm{BH}_{3}\right.$ and $\left.\mathrm{W}(\mathrm{CO})_{5}\right)$ are in the narrow range of 1.513 to $1.517 \AA$ and are nearly identical to the values found in the Lewis acid free BN and BNBN adducts (1.517 and $1.510 \AA$, respectively). However, in the donor-acceptor complexes, the B-N bond lengths in BN and BNBN slightly increase by 0.001-0.035 $\AA$ showing (modest) $\pi$-electron transfer from the $\mathrm{B}-\mathrm{N}$ bond to the LA molecule. The computed N-B and N-W bond lengths for the BN and BNBN adducts (1.521-1.627 $\AA$ and 2.155-2.332 $\AA$, respectively) are shorter than the BP86/TZ2P values for the $\mathrm{H}_{3} \mathrm{~N}-\mathrm{BH}_{3}$ and $\mathrm{H}_{3} \mathrm{~N}-\mathrm{W}(\mathrm{CO})_{5}$ complexes (1.657 and $2.350 \AA$, respectively) due to a change in hybridization at nitrogen from $\mathrm{sp}^{3}$ to formally $\mathrm{sp} .{ }^{95}$

Overall, $\mathrm{W}(\mathrm{CO})_{5}$ appears to be a stronger Lewis acid compared to $\mathrm{BH}_{3}$ as the $\Delta G^{\circ}$ values for the former adduct series are more favorable (negative) by $9.3-15.5 \mathrm{kcal} \mathrm{mol}^{-1}$ (Fig. 7); a
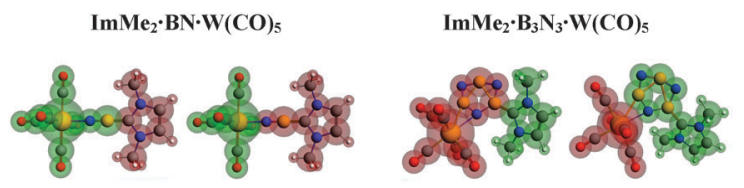

Fig. 8 Different fragments (shown in green and red colors) utilized for the EDA-NOCV computations of the $\mathrm{C}-\mathrm{B}$ and $\mathrm{N}-\mathrm{W}$ bonds in the $\operatorname{ImMe} 2 \cdot \mathrm{BN}$. $\mathrm{W}(\mathrm{CO})_{5}$ and $\operatorname{ImMe}_{2} \cdot \mathrm{B}_{3} \mathrm{~N}_{3} \cdot \mathrm{W}(\mathrm{CO})_{5}$ adducts.

similar conclusion regarding the relative Lewis acidity of $\mathrm{W}(\mathrm{CO})_{5}$ versus $\mathrm{BH}_{3}$ has been made previously. ${ }^{46}$ These results support our experimental results within the IPr $\cdot \mathrm{GeH}_{2} \cdot \mathrm{LA}$ complexes $\left(\mathrm{LA}=\mathrm{BH}_{3}\right.$ and $\left.\mathrm{W}(\mathrm{CO})_{5}\right)$ where the $\mathrm{W}(\mathrm{CO})_{5}$ adduct is more stable. $^{25}$

The impact of complexing $\mathrm{ImMe}_{2}$ and $\mathrm{BH}_{3}$ molecules concurrently to the $\mathrm{B}_{2} \mathrm{~N}_{2}$ and $\mathrm{B}_{3} \mathrm{~N}_{3}$ units was studied. More specifically, the Gibbs free energies for the addition of the $\mathrm{ImMe}_{2}$ ligand to the $\operatorname{ImMe}_{2} \cdot \mathrm{B}_{2} \mathrm{~N}_{2} \cdot\left(\mathrm{BH}_{3}\right)_{2}$ and $\left(\operatorname{ImMe}_{2}\right)_{2} \cdot \mathrm{B}_{3} \mathrm{~N}_{3} \cdot\left(\mathrm{BH}_{3}\right)_{3}$ adducts to form the fully saturated $\left(\mathrm{ImMe}_{2}\right)_{2} \cdot \mathrm{B}_{2} \mathrm{~N}_{2} \cdot\left(\mathrm{BH}_{3}\right)_{2}$ and $\left(\mathrm{ImMe}_{2}\right)_{3} \cdot \mathrm{B}_{3} \mathrm{~N}_{3} \cdot\left(\mathrm{BH}_{3}\right)_{3}$ complexes were found to be -74.2 and $-60.9 \mathrm{kcal} \mathrm{mol}^{-1}$, respectively (Table S10, ESI $\dagger$ ).

Table 4 Computed EDA-NOCV components (in kcal mol ${ }^{-1}$ ) for the C-B and $\mathrm{N}-\mathrm{W}$ bonds of the $\operatorname{ImMe} 2 \cdot \mathrm{BN} \cdot \mathrm{W}(\mathrm{CO})_{5}$ and $\operatorname{ImMe}_{2} \cdot \mathrm{B}_{3} \mathrm{~N}_{3} \cdot \mathrm{W}(\mathrm{CO})_{5}$ adducts at the BP86/TZ2P level of theory. The analogous values for the $\mathrm{C}-\mathrm{B}$ bonds without Lewis acid are also provided in parenthesis. See Fig. 8 for the corresponding fragments

\begin{tabular}{|c|c|c|c|c|}
\hline & \multicolumn{2}{|c|}{$\mathrm{ImMe}_{2} \cdot \mathrm{BN} \cdot \mathrm{W}(\mathrm{CO})_{5}$} & \multicolumn{2}{|c|}{$\mathrm{ImMe}_{2} \cdot \mathrm{B}_{3} \mathrm{~N}_{3} \cdot \mathrm{W}(\mathrm{CO})_{5}$} \\
\hline & C-B & $\mathrm{N}-\mathrm{W}$ & C-B & $\mathrm{N}-\mathrm{W}$ \\
\hline$\Delta E_{\text {int }}$ & $-172.6(-136.1)$ & -57.6 & $-92.0(-93.8)$ & -45.1 \\
\hline$\Delta E_{\text {Pauli }}$ & $151.1(211.6)$ & 106.5 & $203.9(220.7)$ & 113.0 \\
\hline$\Delta E_{\text {elstat }}$ & $-154.4(-168.3)$ & -105.7 & $-151.5(-158.1)$ & -89.8 \\
\hline$\Delta E_{\text {orb }}$ & $-169.4(-179.3)$ & -58.4 & $-146.2(-154.6)$ & -68.3 \\
\hline$\Delta E_{\text {orb }, \sigma}$ & $-113.5(-115.8)$ & -31.6 & $-112.9(-118.8)$ & -26.7 \\
\hline$\Delta E_{\mathrm{orb}, \pi}$ & $-30.9(-40.5)$ & -10.7 & $-16.7(-10.9)$ & -26.9 \\
\hline$\Delta E_{\text {orb,rest }}$ & $-25.0(-19.5)$ & -16.1 & $-16.6(-24.9)$ & -14.7 \\
\hline
\end{tabular}




\subsection{EDA-NOCV for $\mathrm{BN}$ and $\mathrm{B}_{3} \mathrm{~N}_{3} \mathrm{LB} / \mathrm{LA}$ substituted adducts}

To further study the impact of adding a Lewis acid on stabilizing $\mathrm{BN}$ and $\mathrm{B}_{3} \mathrm{~N}_{3}$ molecules, $\mathrm{C}-\mathrm{B}$ and $\mathrm{N}-\mathrm{W}$ bonds in the $\mathrm{ImMe}_{2} \cdot \mathrm{BN}$. $\mathrm{W}(\mathrm{CO})_{5}$ and $\mathrm{ImMe}_{2} \cdot \mathrm{B}_{3} \mathrm{~N}_{3} \cdot \mathrm{W}(\mathrm{CO})_{5}$ adducts were examined using the EDA-NOCV approach (Fig. 8 and Table 4); their corresponding deformation densities are presented in Fig. 9.

Comparing the interaction energies in the $\mathrm{BN}$ and the $\mathrm{B}_{3} \mathrm{~N}_{3}$ adducts reveals that the $\mathrm{C}-\mathrm{B}$ bond becomes $36.5 \mathrm{kcal} \mathrm{mol}^{-1}$ stronger upon $\mathrm{W}(\mathrm{CO})_{5}$ Lewis acid attachment in the former adduct, but surprisingly it becomes $1.8 \mathrm{kcal} \mathrm{mol}^{-1}$ weaker in the latter (Fig. 7). More specifically, addition of tungsten pentacarbonyl as a Lewis acid significantly decreases the Pauli repulsion portion of the $\mathrm{C}-\mathrm{B}$ bond; from $211.6 \mathrm{kcal} \mathrm{mol}{ }^{-1}$ in $\mathrm{ImMe}_{2} \cdot \mathrm{BN}$ to $151.1 \mathrm{kcal} \mathrm{mol}{ }^{-1}$ in $\mathrm{ImMe}_{2} \cdot \mathrm{BN} \cdot \mathrm{W}(\mathrm{CO})_{5}$ but increases it from $203.9 \mathrm{kcal} \mathrm{mol}^{-1}$ in $\mathrm{ImMe}_{2} \cdot \mathrm{B}_{3} \mathrm{~N}_{3}$ to $220.7 \mathrm{kcal} \mathrm{mol}{ }^{-1}$ in $\mathrm{ImMe}_{2}$. $\mathrm{B}_{3} \mathrm{~N}_{3} \cdot \mathrm{W}(\mathrm{CO})_{5}$ (Fig. 7). Lewis acid attachment also decreases the contribution of electrostatic and orbital interactions by 13.9 and $9.9 \mathrm{kcal} \mathrm{mol}^{-1}$ for $\mathrm{ImMe}_{2} \cdot \mathrm{BN}$ adduct but it increases them to 6.6 and $8.4 \mathrm{kcal} \mathrm{mol}{ }^{-1}$ for the $\operatorname{ImMe}_{2} \cdot \mathrm{B}_{3} \mathrm{~N}_{3}$ adduct. An inspection of the $\sigma$ and $\pi$ orbital interaction components for the $\mathrm{C}-\mathrm{B}$ bonds in the $\mathrm{BN}$ adduct proves that the decrease in $\Delta E_{\text {orb }}$ upon bonding to the Lewis acid comes mainly from the decrease of $\pi$-backbonding rather than $\sigma$-donation. Moreover, comparing the percent contribution of the $\Delta E_{\text {orb }}$ component to the total interaction energy confirms the ionic nature of the $\mathrm{N}-\mathrm{W}$ bonds (35.6\% and $43.2 \%$ for the $\mathrm{BN}$ and $\mathrm{B}_{3} \mathrm{~N}_{3}$ adducts, respectively). It is also worthwhile mentioning that no stationary point was found for the $\mathrm{BN} \cdot \mathrm{W}(\mathrm{CO})_{5}$ or $\mathrm{B}_{3} \mathrm{~N}_{3} \cdot \mathrm{W}(\mathrm{CO})_{5}$ adducts which points towards the instability of the $\mathrm{N}-\mathrm{W}$ bond in these species in the absence of the Lewis base.

Given that the free energies of complexation associated with coordinating $\mathrm{ImMe}_{2} \cdot \mathrm{BN}$ and $\mathrm{ImMe}_{2} \cdot \mathrm{BNBN}$ units by $\mathrm{BH}_{3}$ and $\mathrm{W}(\mathrm{CO})_{5}$ are quite favorable, Lewis acid coordination can provide even more stability for these highly elusive boron nitride species, ${ }^{83,97,98}$ and research towards preparing these compounds in the laboratory is ongoing.

\section{Conclusions}

A variety of acyclic and cyclic $(\mathrm{BN})_{n}(n=1-3)$ adducts with different Lewis bases including an N-heterocyclic carbene, an $\mathrm{N}$-heterocyclic olefin and a Wittig donor were examined using M05-2X/cc-pVTZ computations. Considering the Gibbs free energies, values greater than $-50 \mathrm{kcal} \mathrm{mol}^{-1}$ were found for the complexation energies. From the NBO, AIM and EDA-NOCV approaches, the existence of a polar covalent bond between carbene and boron atom was confirmed in each adduct studied. On the other hand, computed NPA charges illustrated rather significant amounts of charge transfer from the carbene center towards the boron atom upon C-B bond formation. A donor-acceptor strategy, in analogy with our synthesis of heavier group 14 element dihydride adducts, ${ }^{14}$ show that LB. $(\mathrm{BN})_{n} \mathrm{~W}(\mathrm{CO})_{5}(n=1-3)$ complexes could be experimentally achievable. Finally, both the $\mathrm{C}-\mathrm{B}$ donor and N-W acceptor bonds were decomposed into their $\sigma$ and $\pi$ bonding components in the ImMe $\mathrm{I}_{2}$ substituted $\mathrm{BN}$ and $\mathrm{B}_{3} \mathrm{~N}_{3}$ adducts with and without $\mathrm{W}(\mathrm{CO})_{5}$ as a Lewis acid. Analysis of the EDA-NOCV results in these adducts showed that the carbene-boron bonds are stronger in the presence of $\mathrm{W}(\mathrm{CO})_{5}$ as a Lewis acid mainly because of a dramatic decrease in Pauli repulsion rather than an increase in the electrostatic/orbital attraction.

\section{Acknowledgements}

This work was supported by the Natural Sciences and Engineering Research Council (NSERC) of Canada (Discovery Grants to A.B. and E.R.), the Canada Foundation of Innovation, and Alberta Innovates-Technology Futures (New Faculty Award to E.R.). L.S. thanks the Undergraduate Research Initiative at the University of Alberta and NSERC (Undergraduate Student Research Award) for financial support. Compute/Calcul Canada is acknowledged for providing computational resources. 


\section{References}

1 R. T. Paine and C. K. Narula, Chem. Rev., 1990, 90, 73-91.

2 D. Golberg, Y. Bando, C. Tang and C. Zhi, Adv. Mater., 2007, 19, 2413-2432.

3 M. Xu, T. Liang, M. Shi and H. Chen, Chem. Rev., 2013, 113, 3766-3798.

4 K. Watanabe, T. Taniguchi and H. Kanda, Nat. Mater., 2004, 3, 404-409.

5 A. K. Geim and I. V. Grigorieva, Nature, 2013, 499, 419-425.

6 C. R. Dean, A. F. Young, I. Meric, C. Lee, L. Wang, S. Sorgenfrei, K. Watanabe, T. Taniguchi, P. Kim, K. L. Shepard and J. Hone, Nat. Nanotechnol., 2010, 5, 722-726.

7 H. Braunschweig, R. D. Dewhurst, K. Hammond, J. Mies, K. Radacki and A. Vargas, Science, 2012, 336, 1420-1422.

8 R. Kinjo, B. Donnadieu, M. A. Celik, G. Frenking and G. Bertrand, Science, 2011, 333, 610-613.

9 Y. Wang, Y. Xie, P. Wei, R. B. King, H. F. Schaefer III, P. von R. Schleyer and G. H. Robinson, Science, 2008, 321, 1069-1071.

10 Y. Wang and G. H. Robinson, Dalton Trans., 2012, 41, 337-345.

11 D. J. D. Wilson and J. L. Dutton, Chem. - Eur. J., 2013, 19, 13626-13637.

12 Y. Wang and G. H. Robinson, Inorg. Chem., 2014, 53, 11815-11832.

13 C. Jones, A. Sidiropoulos, N. Holzmann, G. Frenking and A. Stasch, Chem. Commun., 2012, 48, 9855-9857.

14 E. Rivard, Dalton Trans., 2014, 43, 8577-8586.

15 K. C. Mondal, H. W. Roesky, A. C. Stückl, F. Ehret, W. Kaim, B. Dittrich, B. Maity and D. Koley, Angew. Chem., Int. Ed., 2013, 52, 11804-11807.

16 U. Vogel, A. Y. Timoshkin and M. Scheer, Angew. Chem., Int. Ed., 2001, 40, 4409-4412.

17 U. Vogel, P. Hoemensch, K.-C. Schwan, A. Y. Timoshkin and M. Scheer, Chem. - Eur. J., 2003, 9, 515-519.

18 K.-C. Schwan, A. Y. Timoskin, M. Zabel and M. Scheer, Chem. - Eur. J., 2006, 12, 4900-4908.

19 C. Marquardt, A. Adolf, A. Stauber, M. Bodensteiner, A. V. Virovets, A. Y. Timoshkin and M. Scheer, Chem. - Eur. J., 2013, 19, 11887-11891.

20 A. Adolf, U. Vogel, M. Zabel, A. Y. Timoshkin and M. Scheer, Eur. J. Inorg. Chem., 2008, 3482-3492.

21 U. Vogel, A. Y. Timoshkin, K.-C. Schwan, M. Bodensteiner and M. Scheer, J. Organomet. Chem., 2006, 691, 4556-4564.

22 A. Y. Timoshkin, Inorg. Chem., 2009, 48, 8145-8153.

23 A. S. Lisovenko and A. Y. Timoshkin, Inorg. Chem., 2010, 49, 10357-10369.

24 K. C. Thimer, S. M. I. Al-Rafia, M. J. Ferguson, R. McDonald and E. Rivard, Chem. Commun., 2009, 7119-7121.

25 S. M. I. Al-Rafia, A. C. Malcolm, S. K. Liew, M. J. Ferguson and E. Rivard, J. Am. Chem. Soc., 2011, 133, 777-779.

26 S. M. I. Al-Rafia, A. C. Malcolm, R. McDonald, M. J. Ferguson and E. Rivard, Angew. Chem., Int. Ed., 2011, 50, 8354-8357.

27 S. M. I. Al-Rafia, A. C. Malcolm, R. McDonald, M. J. Ferguson and E. Rivard, Chem. Commun., 2012, 48, 1308-1310.
28 S. M. I. Al-Rafia, O. Shynkaruk, S. M. McDonald, S. K. Liew, M. J. Ferguson, R. McDonald, R. H. Herber and E. Rivard, Inorg. Chem., 2013, 52, 5581-5589.

29 S. M. I. Al-Rafia, M. R. Momeni, M. J. Ferguson, R. McDonald, A. Brown and E. Rivard, Organometallics, 2013, 32, 6658-6665.

30 S. M. I. Al-Rafia, A. C. Malcolm, S. K. Liew, M. J. Ferguson, R. McDonald and E. Rivard, Chem. Commun., 2011, 47, 6987-6989.

31 A. K. Swarnakar, S. M. McDonald, K. C. Deutsch, P. Choi, M. J. Ferguson, R. McDonald and E. Rivard, Inorg. Chem., 2014, 53, 8662-8671.

32 Y. Zhao, N. E. Schultz and D. G. Truhlar, J. Chem. Theory Comput., 2006, 2, 364-382.

33 T. H. Dunning Jr., J. Chem. Phys., 1990, 90, 1007-1023.

34 D. E. Woon and T. H. Dunning Jr., J. Chem. Phys., 1993, 98, 1358-1371.

35 K. A. Peterson and C. Puzzarini, Theor. Chem. Acc., 2005, 114, 283-296.

36 D. Figgen, K. A. Peterson, M. Dolg and H. Stoll, J. Chem. Phys., 2009, 130, 164108.

37 D. Feller, J. Comput. Chem., 1996, 17, 1571-1586.

38 K. L. Schuchardt, B. T. Didier, T. Elsethagen, L. Sun, V. Gurumoorthi, J. Chase, J. Li and T. L. Windus, J. Chem. Inf. Model., 2007, 47, 1045-1052.

39 A. D. Becke, Phys. Rev. A: At., Mol., Opt. Phys., 1988, 38, 3098-3100.

40 J. P. Perdew, Phys. Rev. B: Condens. Matter Mater. Phys., 1986, 33, 8822-8824.

41 T. H. Dunning, J. Chem. Phys., 1971, 55, 716-723.

42 K. Morokuma, J. Chem. Phys., 1971, 55, 1236-1244.

43 T. Ziegler and A. Rauk, Theor. Chim. Acta, 1977, 46, 1-10.

44 F. M. Bickelhaupt and E. J. Baerends, Rev. Comput. Chem., 2000, 15, 1-86.

45 G. TeVelde, F. M. Bickelhaupt, E. J. Baerends, C. Fonseca Guerra, S. J. A. Van Gisbergen, J. G. Shijders and T. Ziegler, J. Comput. Chem., 2001, 22, 931-967.

46 G. Frenking, K. Wichmann, N. Fröhlich, C. Loschen, M. Lein, J. Frunzke and V. M. Rayón, Coord. Chem. Rev., 2003, 238, 55-82.

47 M. Lein and G. Frenking, Theory and Applications of Computational Chemistry: The First 40 Years, Elsevier, Amsterdam, 2001, pp. 367-414.

48 G. Frenking and F. M. Bickelhaupt, The Chemical Bond. 1. Fundamental Aspects of Chemical Bonding, Wiley-VCH, Weinheim, Amsterdam, 2014, pp. 121-158.

49 M. P. Mitoraj, A. Michalak and T. Ziegler, J. Chem. Theory Comput., 2009, 5, 962-975.

50 E. D. Glendening, A. E. Reed, J. E. Carpenter and F. Weinhold, NBO Version 3.1.

51 R. F. W. Bader, Atoms in Molecules: A Quantum Theory, Oxford University Press, Oxford, 1990.

52 M. J. Frisch, G. W. Trucks, H. B. Schlegel, G. E. Scuseria, M. A. Robb, J. R. Cheeseman, G. Scalmani, V. Barone, B. Mennucci, G. A. Petersson, H. Nakatsuji, M. Caricato, X. Li, H. P. Hratchian, A. F. Izmaylov, J. Bloino, G. Zheng, 
J. L. Sonnenberg, M. Hada, M. Ehara, K. Toyota, R. Fukuda, J. Hasegawa, M. Ishida, T. Nakajima, Y. Honda, O. Kitao, H. Nakai, T. Vreven, J. A. Montgomery Jr., J. E. Peralta, F. Ogliaro, M. Bearpark, J. J. Heyd, E. Brothers, K. N. Kudin, V. N. Staroverov, R. Kobayashi, J. Normand, K. Raghavachari, A. Rendell, J. C. Burant, S. S. Iyengar, J. Tomasi, M. Cossi, N. Rega, J. M. Millam, M. Klene, J. E. Knox, J. B. Cross, V. Bakken, C. Adamo, J. Jaramillo, R. Gomperts, R. E. Stratmann, O. Yazyev, A. J. Austin, R. Cammi, C. Pomelli, J. W. Ochterski, R. L. Martin, K. Morokuma, V. G. Zakrzewski, G. A. Voth, P. Salvador, J. J. Dannenberg, S. Dapprich, A. D. Daniels, Ö. Farkas, J. B. Foresman, J. V. Ortiz, J. Cioslowski and D. J. Fox, Gaussian 09 Revision B.1, Gaussian Inc., Wallingford CT, 2009.

53 T. A. Keith, AIMAll (version 13.01.27), TK Gristmill Software: Overland Park, KS, USA, 2013.

54 P. von R. Schleyer, C. Maerker, A. Dransfeld, H. Jiao and N. J. R. v. E. Hommes, J. Am. Chem. Soc., 1996, 118, 6317-6318. 55 ADF2013, SCM, Theoretical Chemistry, Vrije Universiteit, Amsterdam, The Netherlands, http://www.scm.com.

56 C. Jones, Chem. Commun., 2001, 2293-2298.

57 N. Kuhn and A. Al-Sheikh, Coord. Chem. Rev., 2005, 249, 829-857. 58 G. Prabusankar, A. Sathyanarayana, P. Suresh, C. N. Babu, K. Srinivas and B. P. R. Metla, Coord. Chem. Rev., 2014, 269, 96-133.

59 N. Kuhn, H. Bohnen, J. Kreutzberg, D. Bläser and R. Boese, J. Chem. Soc., Chem. Commun., 1993, 1136-1137.

60 A. Fürstner, M. Alcarazo, R. Goddard and C. W. Lehmann, Angew. Chem., Int. Ed., 2008, 47, 3210-3214.

61 A. Dumrath, X.-F. Wu, H. Neumann, A. Spannenberg, R. Jackstell and M. Beller, Angew. Chem., Int. Ed., 2010, 49, 8988-8992.

62 A. C. Malcolm, K. J. Sabourin, R. McDonald, M. J. Ferguson and E. Rivard, Inorg. Chem., 2012, 51, 12905-12916.

63 S. M. I. Al-Rafia, M. R. Momeni, R. McDonald, M. J. Ferguson, A. Brown and E. Rivard, Angew. Chem., Int. Ed., 2013, 52, 6390-6395.

64 Y. Wang, M. Y. Abraham, R. J. Gilliard, Jr., D. R. Sexton, P. Wei and G. H. Robinson, Organometallics, 2013, 32, 6639-6642.

65 R. S. Ghadwal, S. O. Reichmann, F. Engelhardt, D. M. Andrada and G. Frenking, Chem. Commun., 2013, 49, 9440-9442.

66 C. J. Berger, G. He, C. Merten, R. McDonald, M. J. Ferguson and E. Rivard, Inorg. Chem., 2014, 53, 1475-1486.

67 H. J. Bestmann, K. Sühs and T. Röder, Angew. Chem., Int. Ed., 1981, 20, 1038-1039.

68 F. Breitsameter, H.-P. Schrödel, A. Schmidpeter, H. Nöth and S. Rojas-Lima, Z. Anorg. Allg. Chem., 1999, 625, 1293-1300.

69 H. Xu, C. U. Pittman Jr. and S. Saebø, Struct. Chem., 2013, 24, 1383-1393.

70 W. Cui, C. Wang, J. Shao and X. Zhu, Int. J. Quantum Chem., 2013, 113, 2251-2260.

71 A. Sutjianto, R. Pandey and J. Manuel Recio, Int. J. Quantum Chem., 1994, 52, 199-210.
72 J. M. L. Martin, J. El-Yazal and J.-P. Francois, Chem. Phys. Lett., 1996, 248, 95-101.

73 J. M. L. Martin, J. El-Yazal, J.-P. Francois and R. Gijbels, Chem. Phys. Lett., 1995, 232, 289-294.

74 J. M. L. Martin, J.-P. François and R. Gijbels, Chem. Phys. Lett., 1992, 193, 243-250.

75 J. M. L. Martin, Mol. Phys., 2014, 112, 785-793.

76 A. Karton and J. M. L. Martin, J. Chem. Phys., 2006, 125, 144313.

77 J. M. L. Martin, T. J. Lee, G. E. Scuseria and P. R. Taylor, J. Chem. Phys., 1992, 97, 6549-6556.

78 D. P. Curran, A. Solovyev, M. Makhlouf Brahmi, L. Fensterbank, M. Malacria and E. Lacôte, Angew. Chem., Int. Ed., 2011, 50, 10294-10317.

79 K. J. Sabourin, A. C. Malcolm, R. McDonald, M. J. Ferguson and E. Rivard, Dalton Trans., 2013, 42, 4625-4632.

80 N. E. Stubbs, T. Jurca, E. M. Leitao, C. H. Woodall and I. Manners, Chem. Commun., 2013, 49, 9098-9100.

81 S. M. I. Al-Rafia, R. McDonald, M. J. Ferguson and E. Rivard, Chem. - Eur. J., 2012, 18, 13810-13820.

82 A. E. Reed and P. von R. Schleyer, J. Am. Chem. Soc., 1990, 112, 1434-1445.

83 P. Paetzold, C. von Plotho, G. Schmid, R. Boese, B. Schrader, D. Bougeard, U. Pfeiffer, R. Gleiter and W. Schäfer, Chem. Ber., 1984, 117, 1089.

84 E. Rivard, W. A. Merrill, J. C. Fettinger, R. Wolf, G. H. Spikes and P. P. Power, Inorg. Chem., 2007, 46, 2971-2978.

85 W. Luthin, G. Elter, A. Heine, D. Stalke, G. M. Sheldrick and A. Meller, Z. Anorg. Allg. Chem., 1992, 608, 147-152.

86 G. Elter, M. Neuhaus, A. Meller and D. Schmidt-Bäse, J. Organomet. Chem., 1990, 381, 299-313.

87 R. A. Bartlett, H. Chen, H. V. Rasika Dias, M. M. Olmstead and P. P. Power, J. Am. Chem. Soc., 1988, 110, 446-449.

88 T. B. Tai and M. T. Nguyen, Angew. Chem., Int. Ed., 2013, 52, 4554-4557.

89 N. Holzmann, A. Stasch, C. Jones and G. Frenking, Chem. Eur. J., 2011, 17, 13517-13525.

90 N. Holzmann, A. Stasch, C. Jones and G. Frenking, Chem. Eur. J., 2013, 19, 6467-6479.

91 M. R. Momeni, E. Rivard and A. Brown, Organometallics, 2013, 32, 6201-6208.

92 S. Sarmah, A. K. Guha and A. K. Phukan, Eur. J. Inorg. Chem., 2013, 3233-3239.

93 C. Loschen, K. Voigt, J. Frunzke, A. Diefenbach, M. Diedenhofen and G. Frenking, Z. Anorg. Allg. Chem., 2002, 628, 1294-1304.

94 F. Bessac and G. Frenking, Inorg. Chem., 2003, 42, 7990-7994. 95 F. Bessac and G. Frenking, Inorg. Chem., 2006, 45, 6956-6964. 96 R. Tonner and G. Frenking, Chem. - Eur. J., 2008, 14, 3273-3289. 97 R. C. Fischer and P. P. Power, Chem. Rev., 2010, 110, 3877-3923.

98 G. He, O. Shynkaruk, M. W. Lui and E. Rivard, Chem. Rev., 2014, 114, 7815-7880. 